\title{
Custos logísticos: mensuração e uso por redes supermercadistas do Estado do Rio Grande do Sul
}

\author{
Marcos Antonio de Souza \\ Doutorado em Controladoria e Contabilidade pela Universidade de São Paulo - USP \\ Professor na Universidade do Vale do Rio dos Sinos - UNISINOS \\ Av. Unisinos, 950. Bairro Cristo Rei. São Leopoldo/RS. CEP: 93022-000 \\ E-mail:marcosas@unisinos.br
}

Rodrigo Machado Correa Mestrado em Ciências Contábeis pela Universidade do Vale do Rio dos Sinos UNISINOS Av. Unisinos, 950. Bairro Cristo Rei. São Leopoldo/RS. CEP: 93022-000 E-mail: rodrigo.0305@hotmail.com

Gustavo Pires Kruger Mestrado em Ciências Contábeis pela Universidade do Vale do Rio dos Sinos UNISINOS

Professor do Centro Universitário La Salle Av. Victor Barreto, 2288. Canoas/RS

E-mail: gustavokruger.professor@hotmail.br

\section{RESUMO}

A existência de um mercado cada vez mais disputado e exigente, muito discutido no âmbito das indústrias de atuação global, também está presente em outros segmentos de atuação mais localizada. É o caso das redes brasileiras de supermercados de pequeno e médio porte, impactadas pela ação das grandes redes nacionais e internacionais. Nesse contexto, a importância da logística no segmento tem sido destacada como uma prática de gestão que pode ajudar as empresas a tornarem-se mais eficientes, eficazes e competitivas. Diante disso, o objetivo deste estudo é analisar os instrumentos, métodos e informações que essas redes de supermercados de pequeno e médio porte utilizam para a mensuração e gerenciamento do macroprocesso logístico de entrada, movimentação interna e saída de mercadorias, visando gerar informações úteis para a gestão. Trata-se de um estudo de caso múltiplo, de natureza exploratória, com abordagem descritiva e qualitativa. A coleta de dados deu-se por meio de entrevista presencial e contou com a participação de gestores de três redes do estado do Rio Grande do Sul. A principal conclusão indica que apesar da importância dada pelos gestores à mensuração dos custos logísticos, a sua aplicação prática ainda está muito distante do que apregoa a literatura.

Palavras-chave: Logística. Custos logísticos. Varejo. Redes de Supermercados. 
Custos logísticos: mensuração e uso por redes supermercadistas do Estado do Rio Grande do Sul Marcos Antonio Souza, Rodrigo Machado Correa, Gustavo Pires Kruger

Logistic Costs: measurement and use by supermarket chain of Rio Grande do Sul state

\section{ABSTRACT}

The existence of a market fierce competition, more demanding and disputed, in the field of global performance industries, also is present in other business and local segments. It is the case of the small and medium Brazilian supermarkets retail chain. The importance of the logistic system in this segment has been emphasized as one management practice that can become the companies most efficient, effectiveness and competitive. In this context, this study aimed to analyze which instruments, methods and information that these small and medium supermarkets chain use for measurement and management the macro logistic process of goods entrance, internal movement and shipping. This is a multiple case study, under exploratory approach, with descriptive and qualitative scope. The data were collected from personnel interview with managers representing three supermarkets chain located at Rio Grande do Sul State. The main results indicate that although the importance given by the managers to the logistic costs its practical application is still so far of what literature proclaims.

Keywords: Logistic. Logistic Cost. Retail. Supermarket Chain.

\section{INTRODUÇÃO}

A ocorrência de transformações ambientais no âmbito de atuação das empresas, particularmente nas três últimas décadas, é um evento já consolidado na literatura, inicialmente marcada com abordagens concentradas no campo das empresas globais, sobretudo nas indústrias. O que se tem observado mais recentemente, mormente nesta última década, é a extrapolação de estudos e análises dessas ocorrências para a esfera das operações de outros segmentos de negócios, tais como comércio e serviços.

No âmbito das atividades de serviços, o estudo de Gião, Vasconcellos e Oliveira Junior (2008) destaca que o processo de offshoring de serviços tem apresentado forte aceleração nas últimas duas décadas. Acrescenta que serviços de call centers, apoio administrativo, sistemas de informática, serviços de engenharia, distribuição, entre outros, estão sendo deslocados para outros países, onde o custo de mão de obra é mais baixo. Em outros casos isso também ocorre porque alguns desses países já desenvolveram competências similares ou até melhores condições de realização que os países desenvolvidos. 
Custos logísticos: mensuração e uso por redes supermercadistas do Estado do Rio Grande do Sul Marcos Antonio Souza, Rodrigo Machado Correa, Gustavo Pires Kruger

Ainda na área de serviços, agora no setor educacional de nível superior, Sguissardi (2008) aborda as transformações nesse mercado em função da inserção das estrangeiras Laureate International Universities (que adquiriu a Universidade AnhenmiMorumbi), da Whitney International University System (adquirente da Faculdade Jorge Amado) e das nacionais Universidade Estácio de Sá e Grupo Anhanguera.

No segmento do comercio varejista, mais especificamente dos supermercados, um importante marco para o desenvolvimento e acirramento da competitividade aconteceu durante a década de 1990. A esse respeito, o estudo de Ferreira, Venâncio e Abrantes (2009) faz ampla abordagem sobre o processo da globalização e destaca a entrada no mercado brasileiro de grandes redes internacionais de supermercados, como a norte-americana Wal Mart, o grupo holandês Royal Hold e o grupo Casino da França. Os autores esclarecem que isso ocorreu num momento onde o cenário nacional ainda era composto em sua maioria por pequenos e médios supermercados.

Pinto (2007) assinala que o aumento da concorrência e as alterações no comportamento dos consumidores, cada vez mais exigentes, têm sido importantes nesse contexto de mudança. $O$ autor acrescenta que a competição crescente entre as redes tem despertado nas empresas a necessidade de: (1) implantar ações mais objetivas, tais como um programa de redução de custos; (2) oferta diferenciada de serviços; (3) melhorias na gestão para obter maior eficiência operacional; (4) obtenção de vantagens comparativas mais sustentáveis, e, para isso, a logística torna-se fundamental. A logística está ligada, principalmente, à centralização ou não das operações e a tecnologia da informação. Essa questão sobre a centralização não é recente. De fato, o estudo de Santos, Gimenez e Mattos (1998) já há 11 anos constatava que apesar da discussão sobre a centralização e a descentralização do abastecimento de lojas, era perceptível, naquela época, uma tendência à centralização da distribuição. Uma das questões que se colocava era saber exatamente até que ponto deveria haver centralização.

O grande desafio enfrentado pelos gestores de pequenas, médias e até grandes redes de supermercados é a identificação, alocação, mensuração e o gerenciamento dos custos das atividades de apoio, tais como as atividades logísticas. É nesse 
Custos logísticos: mensuração e uso por redes supermercadistas do Estado do Rio Grande do Sul Marcos Antonio Souza, Rodrigo Machado Correa, Gustavo Pires Kruger

aspecto, conforme entendimento de Faria e Costa (2007), que a informação contábil, particularmente a de custos, pode contribuir de forma relevante. Assim, a contabilidade deve atuar como um instrumento essencial para a gestão dos supermercados e não somente como um meio para atender às exigências legais.

Diante dessa realidade, o objetivo deste estudo é analisar como a informação contábil relacionada ao custo do processo logístico vem sendo mensurada, evidenciada e utilizada no processo de gestão de redes supermercadistas de pequeno e médio porte do Rio Grande do Sul. Esse objetivo resulta da seguinte questão de pesquisa: como ocorre a mensuração e uso dos custos logísticos na gestão de redes de supermercados de pequeno e médio porte do Rio Grande do Sul?

A relevância e contribuição de estudos dessa temática já há algum tempo tem chamado a atenção de outros pesquisadores, constatada pela sua explícita ou implícita consideração em estudos semelhantes. Os estudos de Yoshizaki e Vidal (2007), Laidens, Teles e Muller (2007), Ricarte (2005), Pinto (2007), Lopez, Guerra e Anastácio (2004), Lira (2005), Conceição e Quintão (2004), Mathews (1996) e De Santa (1998) são alguns exemplos.

O artigo está estruturado em quatro seções, iniciando com esta introdução. $\mathrm{Na}$ sequência é apresentado o conteúdo do referencial teórico e os aspectos metodológicos utilizados. Continua com a apresentação e análise dos dados, das conclusões do estudo e das referências utilizadas na pesquisa.

\section{REFERENCIAL TEÓRICO}

\subsection{Evolução do Conceito de Logística}

Em um ambiente altamente competitivo, questões como diferenciação, otimização do uso de custos e processos operacionais - que objetivam a excelência dos processos de uma organização - têm sido foco de grande atenção nas empresas.

O aumento da competitividade no mercado, fruto da globalização, e o consequente aumento dos padrões de exigência dos consumidores, gerou a necessidade de reorganização dos modelos de gestão empresarial. Segundo Bowersox 
Custos logísticos: mensuração e uso por redes supermercadistas do Estado do Rio Grande do Sul Marcos Antonio Souza, Rodrigo Machado Correa, Gustavo Pires Kruger

et al. (2000), essa reorganização tem o fim de compatibilizar padrões internacionais de qualidade, produtividade e custo entre as organizações, o que faz da logística um diferencial competitivo.

Pela definição do Council of Logistics Management (1998), corroborada por Lambert, Cooper e Pagh (1998), logística é o processo de planejar, implementar e controlar de maneira eficiente o fluxo e a armazenagem de produtos, bem como os serviços e informações associados, cobrindo desde o ponto de origem até o ponto de consumo.

Sua principal meta, segundo Ballou (2001), é garantir a disponibilidade de produtos, materiais ou serviços no mercado e pontos consumidores, no tempo exato e na condição desejada, ao menor custo possível. Isto é conseguido por meio de administração das funções- chave da logística: transporte, estocagem, distribuição, localização, serviço ao cliente e várias atividades adicionais de apoio.

A logística moderna é denominada de gerenciamento da cadeia de suprimentos ou supply chain management (SCM). Segundo Christopher (1997, p.13), "a cadeia de suprimentos representa uma rede de organizações, através de ligação nos dois sentidos, dos diferentes processos e atividades que produzem valor na forma de produtos e serviços que são colocados nas mãos do consumidor final".

O conceito de SCM surge então, como uma evolução do conceito tradicional de logística. Enquanto a Logística interna representa a integração interna de atividades, a SCM representa sua integração externa, interligando fornecedores aos consumidores finais, e reconhecendo que a integração interna por si só não é suficiente. A Figura 1 apresenta o conceito de logística integrada, focalizando os elos que intermedeiam a ligação fornecedor-consumidor. Além disso, expõe os fluxos que se auto-alimentam na relação demanda-produtos, complementado pelo fluxo simultâneo de informações entre os vários elementos da cadeia.

A evolução do conceito da logística, entretanto, passa pela compreensão de que a integração entre os elos internos (da empresa) e externos (dos demais participantes) da cadeia de suprimentos é uma tarefa complexa e geralmente implementada no longo prazo. Um dos motivos, conforme Goldsby e Closs (2000), é a falta de conhecimento e 
entendimento do conceito de cadeia de suprimentos, assim como dos benefícios dessa integração. Outra explicação dada por Barski e Ellinger (2001), é a necessidade de mudança cultural: antes do surgimento do conceito de gerenciamento da cadeia de suprimentos as práticas comerciais e de negócios entre os participantes da cadeia se baseavam, e em alguns casos ainda se baseiam, na relação de perde/ganha (ou jogo de soma zero), em que um elo busca levar vantagem sobre o outro.

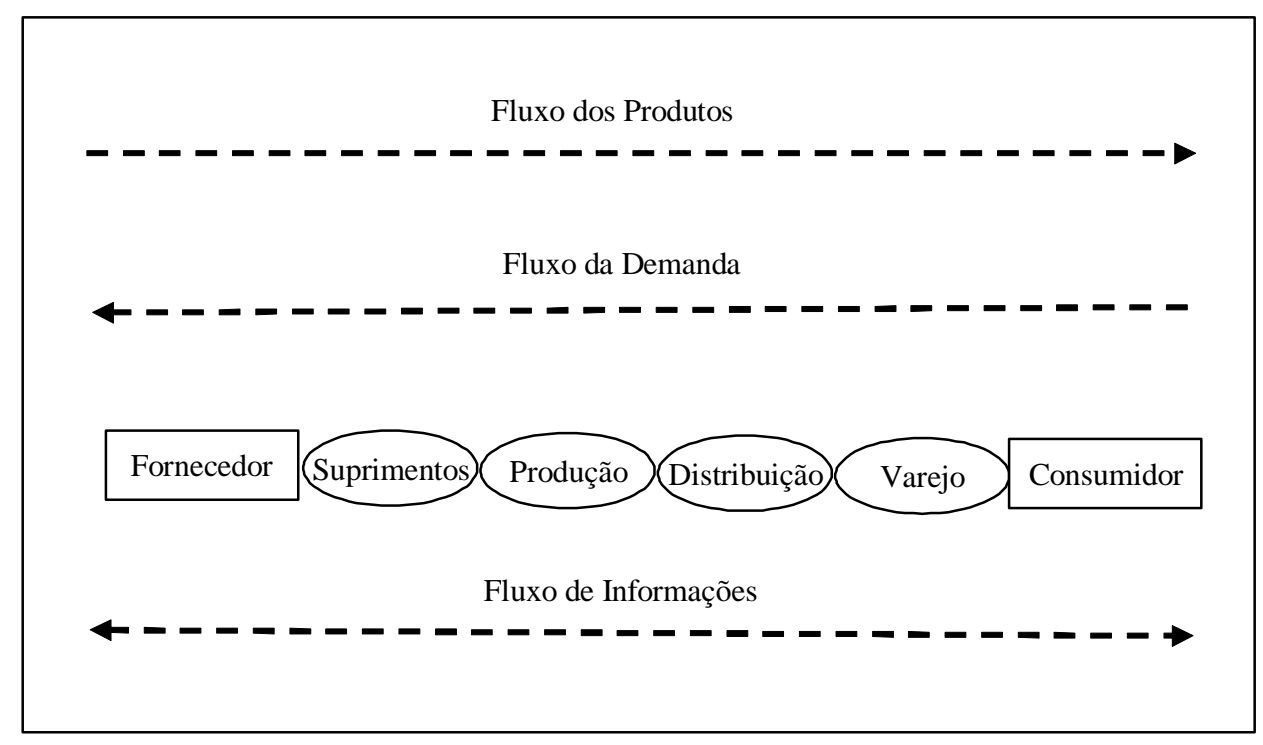

Figura 1: A Integração Logística

Fonte: Bowersox e Closs (2001).

Christopher (1999) entende que existem três subdivisões naturais da logística na empresa: (1) logística de entrada (inbound logistics), que se refere ao suprimento dos insumos; (2) logística interna (material handling), que focaliza a movimentação dos materiais dentro do estabelecimento; (3) logística de saída (outbound logistics), que enfoca a distribuição dos produtos acabados ao consumidor. É o que está representado na Figura 2. 


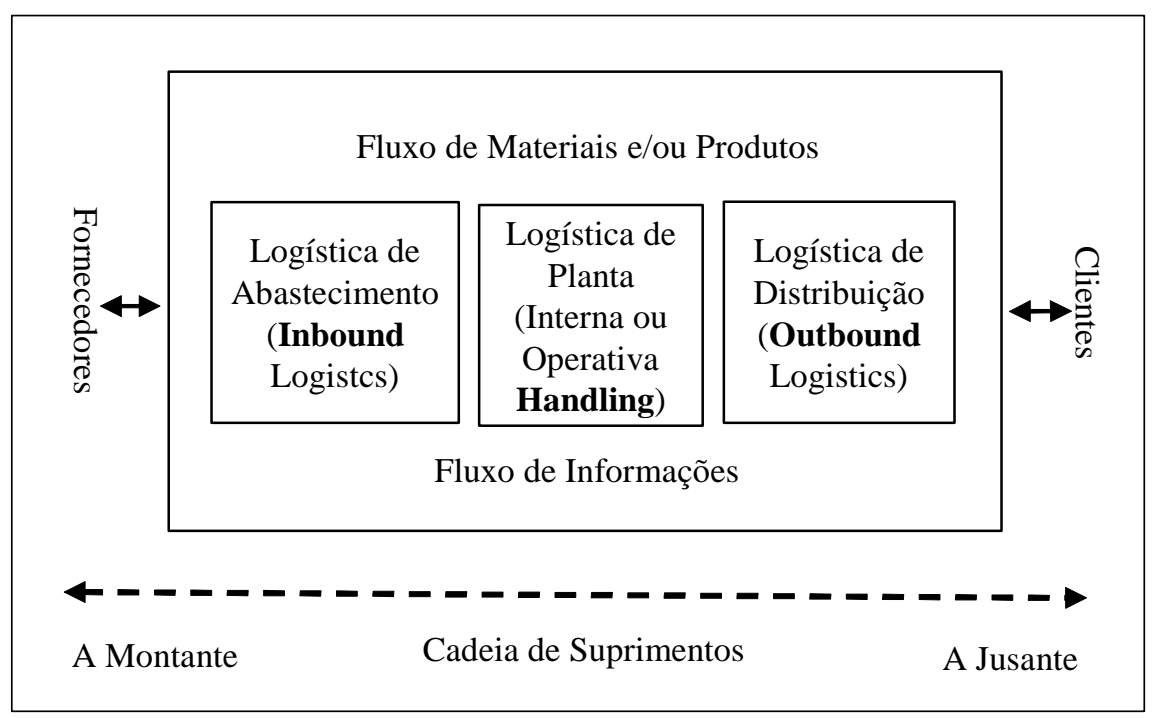

Figura 2: Processos da Cadeia de Suprimentos

Fonte: Adaptado de Christopher (1999).

\subsection{Origem e Fases da Logística}

Embora somente nos últimos anos a logística tenha sido amplamente difundida, ela já tinha sido utilizada desde o início do século XX no transporte de escoamento agrícola, conforme revela estudo de Daher, Silva e Fonseca (2006). Acrescentam que durante a década de 1940, com a Segunda Guerra Mundial, a logística passou a ser aplicada nas forças armadas; daí a origem estar muito ligada às operações militares. No final da guerra, a logística começa a existir como ciência e, durante todos estes anos decorridos desde a segunda guerra, passou por uma continuada evolução. Atualmente, segundo Conceição e Quintão (2004), é considerada um dos elementos fundamentais na estratégia competitiva das empresas.

A primeira fase da logística, segundo Bowersox e Closs (2001), consistia apenas em um atendimento da capacidade ociosa da indústria do pós-guerra, onde se observavam estoques intermediários na manufatura de produtos com pouca diferenciação. Nesta fase o mercado pouco influía, simplesmente agindo na pronta aquisição do que era produzido.

Para Bowersox e Closs (2001), com a evolução das técnicas de produção e de marketing, o mercado começou a demandar produtos com maior grau de diferenciação. Para atender a esta nova demanda, a indústria e o varejo passaram a compartilhar 
Custos logísticos: mensuração e uso por redes supermercadistas do Estado do Rio Grande do Sul Marcos Antonio Souza, Rodrigo Machado Correa, Gustavo Pires Kruger

informações visando reduzir os custos logísticos. Nesta segunda fase ainda predominava uma integração que não continha flexibilidade de ação, ou seja, as informações trocadas não geravam ações corretivas significativas.

$\mathrm{Na}$ terceira fase da logística, ainda de acordo com Bowersox e Closs (2001), o intercâmbio se intensificou e as informações passaram a gerar ações corretivas, com as empresas passando a operar de forma harmônica, inclusive com a troca eletrônica de dados, o que facilitou ainda mais o processo. Também se verificou a procura pelo menor estoque possível durante as fases de produção, distribuição e comercialização, ou seja, a implementação da técnica do just-in-time. Este estoque mínimo era objetivo tanto dentro da própria empresa como nas empresas que operassem em conjunto.

$\mathrm{Na}$ quarta e última fase da logística, conforme discutido por Cooper, Lambert e Pagh (1997), ocorre uma evolução em termos de qualidade na importância da logística. As empresas, com o objetivo de reduzir custos de transporte, agora se relacionavam não somente com os pares e com trocas de informações de produção e vendas, mas à troca de informações estratégicas com a finalidade de alcançar vantagens competitivas pela diferenciação. Neste momento surgiu o conceito de gerenciamento da cadeia de suprimentos (supply chain management), onde um grupo de empresas, de forma alinhada, ajusta suas necessidades com os menores custos possíveis, pois tem objetivos comuns.

Aliado aos conceitos de Bowersox e Closs (1996) e Cooper, Lambert e Pagh (1997), Wood e Zuffo (1998) apresentam adaptações visando, talvez, melhor especificar as principais fases da logística. O Quadro 1 mostra as principais fases do conceito de logística nessa versão adaptada. 
Custos logísticos: mensuração e uso por redes supermercadistas do Estado do Rio Grande do Sul Marcos Antonio Souza, Rodrigo Machado Correa, Gustavo Pires Kruger

\begin{tabular}{|c|c|c|c|c|}
\hline Fase 0 & Fase I & Fase II & Fase III & Fase IV \\
\hline $\begin{array}{c}\text { Administração } \\
\text { de Materiais }\end{array}$ & $\begin{array}{l}\text { Administração } \\
\text { de Materiais } \\
\text { + Distribuição }\end{array}$ & $\begin{array}{l}\text { Logística } \\
\text { Integrada }\end{array}$ & $\begin{array}{l}\text { Supply Chain } \\
\text { Management } \\
\text { (SCM) }\end{array}$ & $\begin{array}{c}\text { Supply Chain } \\
\text { Management } \\
\text { (SCM) } \\
+ \text { ECR } \\
\end{array}$ \\
\hline $\begin{array}{l}\text { Gestão de } \\
\text { Estoques } \\
\text { Gestão de } \\
\text { Compras } \\
\text { Movimentação de } \\
\text { Materiais }\end{array}$ & $\begin{array}{l}\text { Otimização do } \\
\text { Sistema de } \\
\text { Transporte }\end{array}$ & $\begin{array}{l}\text { Visão Sistêmica } \\
\text { da Empresa } \\
\text { Integração por } \\
\text { Sistemas de } \\
\text { Informações }\end{array}$ & $\begin{array}{l}\text { Visão Sistêmica } \\
\text { da Empresa } \\
\text { Incluindo } \\
\text { Fornecedores } \\
\text { e Canais de } \\
\text { Distribuição }\end{array}$ & $\begin{array}{l}\text { Amplo Uso de } \\
\text { Alianças } \\
\text { Estratégicas } \\
\text { Co-Makership } \\
\text { Sub-Contratação } \\
\text { e Canais } \\
\text { Alternativos de } \\
\text { Distribuição }\end{array}$ \\
\hline $\begin{array}{l}\text { Anos } 60 \\
\text { Dist. Física }\end{array}$ & $\begin{array}{c}\text { Anos } 70 \\
\text { Fornecedores }\end{array}$ & $\begin{array}{c}\text { Anos } 80 \\
\text { Dist. Física + } \\
\text { Suprimentos }\end{array}$ & $\begin{array}{c}\text { Integração } \\
\text { Total }\end{array}$ & Globalização \\
\hline
\end{tabular}

Quadro 1: Fases da Logística

Fonte: Adaptado Wood e Zuffo (1998).

Wood e Zuffo (1998) afirmam que o emprego da logística nas empresas tem ganhado diferentes definições, elementos e classificação temporal, porém, em síntese, sempre correspondendo a uma crescente amplitude de escopo, experimentada ao longo do tempo. No cenário brasileiro, Novaes (2004) afirma que muitas empresas ainda estão atuando na primeira fase da logística, ao passo que poucas já atuam utilizando todas as possibilidades da quarta fase, notadamente as multinacionais. $O$ autor assinala que este atraso na evolução se deve aos problemas oriundos das estruturas organizacionais clássicas observadas na maioria das empresas brasileiras. Esta departamentalização inibe a visão sistêmica dos processos e faz com que as empresas se voltem para processos internos não alinhados.

\subsection{Gestão Colaborativa na Cadeia de Suprimentos}

A informação sempre foi um recurso de grande importância nas operações logísticas. Porém, atualmente, com as possibilidades oferecidas pelo avanço tecnológico, ela tem se revelado, segundo Cooke (2006), a força motriz para alavancar a implantação da estratégia competitiva da logística. De fato, no entendimento de Ferreira e Alves (2005), a transferência e o gerenciamento eletrônico das informações 
Custos logísticos: mensuração e uso por redes supermercadistas do Estado do Rio Grande do Sul Marcos Antonio Souza, Rodrigo Machado Correa, Gustavo Pires Kruger

permitem às empresas reduzir seus custos mediante melhor coordenação e uso dos recursos. Além disso, possibilita também a prestação de um serviço de maior qualidade, devido principalmente à melhoria de oferta de informações úteis aos clientes.

Em termos de tecnologia da informação, existem diversas soluções disponíveis para a aplicação na área da logística. Entre as iniciativas de planejamento e gestão colaborativa na cadeia de suprimentos, Pires (2004) destaca: Resposta Eficiente ao Consumido (Efficient Consumer Response - ECR); Estoque Gerenciado pelo Fornecedor (Vendor Management Inventory - VMI); Reposição Contínua (Continuous Replenishment - CR) e Planejamento, Previsão e Reposição/Reabastecimento Colaborativo (Collaborative Planning, Forecasting and Replenishment - CPFR), todos eles apoiados por Troca Eletrônica de Informações (Electronic Data Interchange - EDI), resumidas na Figura 3.

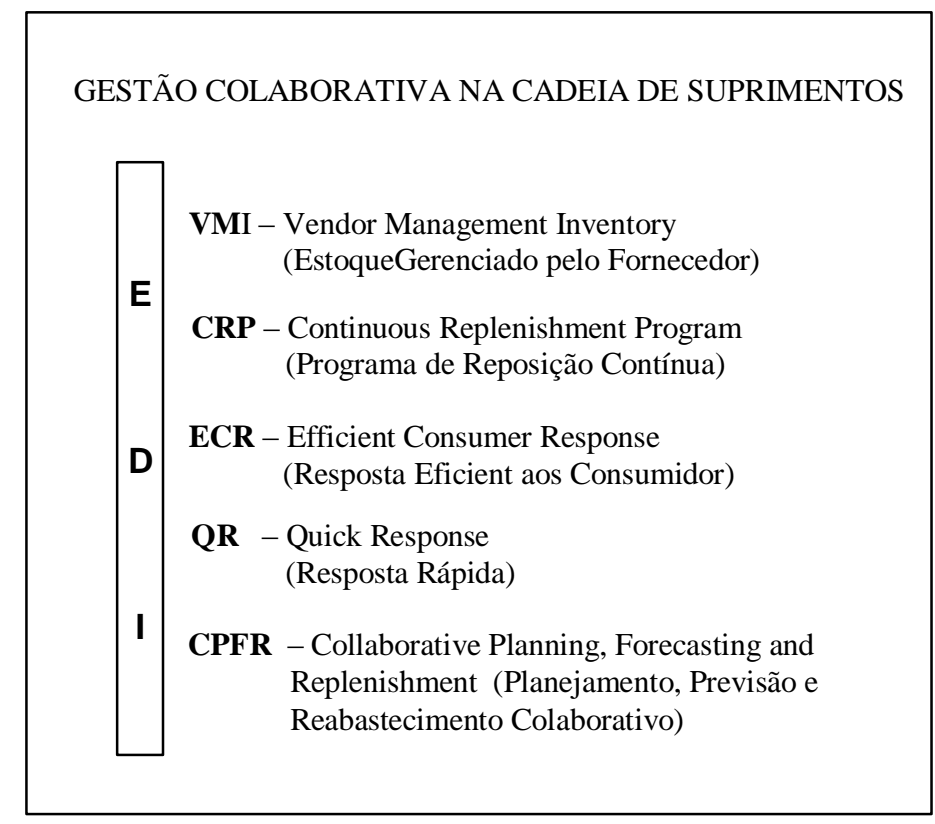

Figura 3: Ferramentas de TI Aplicáveis à Logística Fonte: Adaptado de Pires (2004).

A aplicabilidade do EDI na gestão logística tem sido já há algum tempo abordada por pesquisadores da área. Bowersox e Closs (2001) enfatizam que o EDI é um meio de transferência eletrônica de dados entre empresas, de computador para computador, em formato padrão. Os autores acrescentam que ele foi primeiramente adotado nos 
Custos logísticos: mensuração e uso por redes supermercadistas do Estado do Rio Grande do Sul Marcos Antonio Souza, Rodrigo Machado Correa, Gustavo Pires Kruger

Estados Unidos, na década de 1980, pelos setores de varejo e de transportes, expandindo mais tarde para os setores automotivo, farmacêutico, dentre outros.

Baseado no estudo de Ribeiro e Ferreira (2003), entre os benefícios proporcionados pela adoção do EDI, pode-se citar: (1) aumento da produtividade interna e externa mediante a transmissão rápida de informações; (2) redução de custos administrativos e operacionais; (3) maior conhecimento a respeito do negócio; (4) relacionamentos mais eficazes no canal; (5) eliminação de informações redundantes; (6) ganho de eficiência; (7) eliminação de erros; (8) redução de estoques; e (9) diminuição do trâmite de papel.

Para Lambert, Cooper e Pagh (1998), essas tecnologias de informação impactam vários processos da empresa, com destaque para a logística, principalmente em transporte, armazenagem, processamento de pedidos e gestão de estoques, afetando significativamente as áreas de suprimentos, movimentação e distribuição.

De outra parte, e a respeito das potenciais economias dos custos de transporte, armazenagem e distribuição, e no âmbito dos produtos hortifrutigranjeiros, Medeiros Neto e Motta (2006) destacam que o acondicionamento em embalagens inapropriadas e técnicas obsoletas de carga e descarga fazem da logística de distribuição uma das principais causas de perda de qualidade dos produtos hortifrutícolas, trazendo prejuízos para produtores e consumidores do setor, desde o momento da colheita até a mesa do consumidor. Entretanto, Medeiros Neto e Mota (2006) acrescentam que algumas tecnologias pós-colheita, amparadas por informações de gestão do processo, poderiam ser aplicadas para diminuir as perdas e manter a qualidade. Eles citam como exemplo o uso de embalagens que respeitem as características do produto, a paletização da carga, a utilização de câmaras frias, o transporte e a armazenagem apropriados.

\subsection{Mensuração e Evidenciação dos Custos Logísticos}

Devido ao atual cenário mercadológico, e a importância crescente das atividades logísticas na rentabilidade das empresas e na agregação de valor ao cliente, os métodos de custeio devem ser adaptados e utilizados de modo a contemplarem, de forma mais apropriada, as informações a respeito dos custos logísticos. 
Custos logísticos: mensuração e uso por redes supermercadistas do Estado do Rio Grande do Sul Marcos Antonio Souza, Rodrigo Machado Correa, Gustavo Pires Kruger

O tradicional método de custeio por absorção agrupa os custos por natureza de gasto e não pelas atividades que os originam. Por conseguinte, não permitem a realização de uma análise detalhada, necessária para a identificação e localização dos custos do processo logístico. Sobre isso, Christopher (1997) afirma que a tradicional contabilidade de custos acaba por tornar-se ineficaz como instrumento gerador de informações para a gestão logística, pois, além das limitações de evidenciação dos custos ela utiliza critérios arbitrários para a alocação de custos indiretos, distorcendo a real lucratividade de produtos e/ou clientes. $\mathrm{Na}$ visão do autor isso ocorre porque os procedimentos de custeio tradicionalmente utilizados pela contabilidade foram originariamente desenvolvidos para medir os custos apenas no nível de produtos, o que, na maioria das vezes, disponibiliza dados inadequados para a análise de lucratividade em outros níveis, como clientes e segmentos de mercado.

Fleury, Wanke e Figueiredo (2000) indicam que se deve procurar desenvolver um sistema de custeio para atender uma atividade, um processo ou, até mesmo, todas as atividades e processos existentes na cadeia logística. Para ele, a gestão de custos logísticos deve extrapolar os limites da empresa e devem ser consideradas as atividades desenvolvidas por outros componentes da cadeia logística. E é nesse contexto das atividades que se insere o método de custeio por atividades (Activity Based Costing - ABC).

Nessa mesma direção, Fleury, Wanke e Figueiredo (2000) afirmam que o ABC pode ser aplicado em qualquer tipo de organização, quer seja indústria, prestadora de serviços ou empresa comercial. Também pode ser aplicado no detalhamento do processo logístico, ou seja, custear toda a cadeia, estendendo-se por toda a organização. Portanto, o $A B C$ sai do foco departamental, privilegiado no tradicional custeio por absorção, e cria instrumentos que possibilitem a segregação dos custos logísticos nas suas mais variadas modalidades e nos diversos elos da cadeia logística. O uso da atividade como elemento de análise é um grande agente facilitador dessa mensuração mais detalhada e específica.

Faria e Costa (2005) acrescentam que com o uso isolado do ABC não é possível detectar se os custos dos produtos são mais altos para certo grupo de clientes ou para 
Custos logísticos: mensuração e uso por redes supermercadistas do Estado do Rio Grande do Sul Marcos Antonio Souza, Rodrigo Machado Correa, Gustavo Pires Kruger

certo canal de distribuição. Porém, o $A B C$, associado ao Gerenciamento Baseado em Atividades (Activity Based Management - ABM) pode facilitar na identificação de oportunidades de melhorias pela eliminação de atividades redundantes dentro da cadeia logística; elos do canal de distribuição com excessivo consumo de recursos ou estruturas alternativas para a distribuição, além de mostrar o montante de custos referentes às atividades logísticas de cada produto.

Visando estruturar um eficiente e eficaz sistema de gerenciamento, outros mecanismos de análise dos custos e resultados envolvidos no ambiente da logística foram desenvolvidos. Além do custeio $A B C$ tem-se a técnica para Custeamento da Cadeia de Suprimento (Total Cost of Ownership - TCO), a Análise da Lucratividade por Cliente (Customer Profitability Analisys - CPA) e a Análise da Lucratividade Direta por Produto (Direct Product Profitability - DPP).

Assim, foram os esforços empreendidos para alcançar o objetivo de aumentar a visão dos custos envolvidos na cadeia logística que levaram ao desenvolvimento dessas novas ferramentas. O Quadro 2 apresenta as características principais de cada uma delas.

\begin{tabular}{|c|c|}
\hline $\begin{array}{c}\text { Ferramentas de } \\
\text { Custeio }\end{array}$ & Definição \\
\hline $\begin{array}{c}\text { TCO (Total Cost of } \\
\text { Ownership) }\end{array}$ & $\begin{array}{c}\text { Parte do princípio de que todos os custos associados com a } \\
\text { aquisição, uso e manutenção de um item são considerados como } \\
\text { critérios de aquisição desse item, e não somente o seu preço de } \\
\text { compra. }\end{array}$ \\
\hline $\begin{array}{c}\text { CPA (Customer } \\
\text { Profitability Analysis) }\end{array}$ & $\begin{array}{c}\text { Parte da mesma premissa do custeio } A B C \text {. Contudo, associam-se } \\
\text { as atividades aos clientes, em termos de receitas e custos, e não } \\
\text { aos produtos. }\end{array}$ \\
\hline DPP (Direct Product \\
Profitability) & $\begin{array}{c}\text { Mensura a rentabilidade dos produtos, considerando o custo de } \\
\text { armazenagem e manuseio/movimentação de cada item específico. } \\
\text { Essa técnica procura identificar os custos incorridos por produto ou } \\
\text { por pedido, à medida que estes se deslocam através da cadeia de } \\
\text { suprimentos. }\end{array}$ \\
\hline
\end{tabular}

Quadro 2: Ferramentas para Gestão do Custo Logístico Fonte: Adaptado de Pires (2004).

De posse destas considerações a respeito das novas técnicas gerenciais de mensuração e análise dos custos logísticos, pode-se observar que cada metodologia tem uma aplicabilidade particular que a difere das demais. Nesse sentido, nota-se que 
Custos logísticos: mensuração e uso por redes supermercadistas do Estado do Rio Grande do Sul Marcos Antonio Souza, Rodrigo Machado Correa, Gustavo Pires Kruger

os fatores principais nessa diferenciação concentram-se: (1) no foco sobre qual atividade logística mensurar; e (2) sobre que tipo de informação é demandada pelo processo decisório.

\subsection{Gestão dos Custos logísticos}

A gestão dos custos logísticos começou a ganhar relevância, de acordo com Pohlen e LaLonde (1994), a partir do momento em que a logística foi interpretada como uma fonte de vantagem competitiva, decorrente de sua capacidade de influir na diferenciação ou na redução de custos dos produtos e/ou serviços, repercutindo na maior rentabilidade da empresa. Assim, o gerenciamento dos custos logísticos tem crescido em importância devido ao aumento de seu impacto no preço e na rentabilidade dos produtos, na rentabilidade dos consumidores e, em última instância, na rentabilidade das corporações. Para tanto, os administradores logísticos necessitam de informações mais detalhadas dos sistemas de custeio a fim de determinar como os produtos, consumidores e canais de distribuição, afetam os custos de provimento dos serviços logísticos.

Christopher (1997) destaca que o gerenciamento logístico é um conceito orientado para o fluxo, com o objetivo de integrar recursos ao longo de todo o trajeto que se estende desde os fornecedores até os clientes finais. Portanto, é desejável que se tenha um meio de avaliar os custos e o desempenho deste fluxo. Nesse sentido, a determinação das medidas de desempenho das atividades logísticas, segundo Novack e Thomas (2004), tem sido um desafio contínuo para todas as organizações por diversas razões, tais como: (1) a logística é um processo mais orientado do que funcional; (2) os serviços logísticos incluem múltiplos resultados como, por exemplo, entrega no prazo, ordem de execução etc., que estão relacionados, pois a falha em algum desses resulta em falhas de todo o processo de serviço logístico; (3) muitas organizações diferentes estão envolvidas nos processos logísticos; e (4) o desempenho logístico muitas vezes difere entre os diversos fornecedores.

O estudo de Chow, Heaver e Henriksson (1994) colaborou de forma relevante para esta visão sobre a gestão, pois possibilitou o entendimento de que a avaliação do 
Custos logísticos: mensuração e uso por redes supermercadistas do Estado do Rio Grande do Sul Marcos Antonio Souza, Rodrigo Machado Correa, Gustavo Pires Kruger

desempenho da logística é multidimensional, envolvendo vários indicadores. Ou seja, nenhum indicador isoladamente é suficiente para medir o desempenho logístico de uma cadeia de suprimentos.

Para o exercício eficiente das atividades logísticas é necessário que os gestores desta área detenham um conhecimento detalhado das informações relativas aos custos logísticos. Para tal, segundo Zanquetto e Pizolatto (2003), a controladoria empresarial deve subsidiar a tomada de decisão possibilitando a realização dos necessários tradeoffs presentes no processo decisório das áreas envolvidas. Assim, na ótica desses autores é necessário que estas informações, entre elas as de custos, sejam fundamentadas em estudos conjuntos das áreas de controladoria, logística, marketing/vendas e de todas as outras atividades relacionadas.

\subsection{Comércio Varejista de Supermercados}

Conforme apresentado por Silva (1995), a palavra comércio originou-se do latim, commercium, que dá origem à mercancia, possuindo significação de comprar e vender com o objetivo econômico de lucro. Já a palavra varejo, de acordo com Levy e Weitz (2000), deriva da palavra francesa retalier, que significa cortar um pedaço ou em pequenas quantidades.

Assim, comércio varejista, segundo Parente (2000), é aquele que adquire um bem (mercadoria) de um fabricante, atacadista, distribuidor, ou até mesmo de outro varejista, com objetivo de revendê-lo em pequenas quantidades diretamente para o consumidor final, sem alterar a sua estrutura original, isto é, sem transformá-lo em outro produto.

Conforme destacam Peter, Churchil e Gilbert (2000), varejista é o intermediário que se dedica principalmente a vender para consumidores finais. Portanto, após comprar mercadoria de fabricantes ou atacadistas, os varejistas dedicam-se a vendas individuais e não em grandes lotes.

O uso do termo supermercado exige que se examinem as suas diversas configurações. Em termos gerais, conforme afirmam Saab, Gimenez e Ribeiro, (2000), os supermercados são lojas de vizinhança, localizadas em bairros, com área superior a 
Custos logísticos: mensuração e uso por redes supermercadistas do Estado do Rio Grande do Sul Marcos Antonio Souza, Rodrigo Machado Correa, Gustavo Pires Kruger

$350 \mathrm{~m}^{2}$. Trabalham com o conceito de auto-serviço, contemplando um mínimo de dois pontos de venda - PDVs. Em geral os produtos comercializados são alimentos, nos setores de mercearia, carnes, frios, laticínios e hortifrutigranjeiros; limpeza; perfumaria; higiene pessoal; bebidas e bazar. Eles acrescentam que as lojas do tipo supermercado podem ainda ser classificadas em pequenas, médias e grandes, com as seguintes características:

a) as pequenas, com área de vendas entre $250 \mathrm{~m}^{2}$ e $1.000 \mathrm{~m}^{2}$, localizam-se em vizinhanças de grande circulação, não possuem estacionamento e, em geral, apresentam pouca variedade de itens e profundidade restrita; estão mais concentradas em artigos de primeira necessidade, onde se verifica um valor médio baixo, pois o cliente compra na maioria das vezes artigos para reposição imediata;

b) nos supermercados de tamanho médio (área de vendas entre $1.000 \mathrm{~m}^{2} \mathrm{e}$ $2.500 \mathrm{~m}^{2}$ ) e grande (área de vendas entre $2.500 \mathrm{~m}^{2}$ e $5.000 \mathrm{~m}^{2}$ ) o perfil de compra é um pouco diferenciado, pois muitos clientes realizam suas compras mensais ou de volume superior à compra de simples reposição. O valor médio em geral é mais alto, pois os clientes, ao realizarem compras mais significativas, apresentam maior chance de adquirir supérfluos - compra por impulso, traduzindo em uma venda com maior margem de lucro. Para lojas com esse perfil de venda, o estacionamento é um serviço indispensável ao cliente.

Kotler e Armstrong (1999) esclarecem, quanto aos supermercados de grande porte, que eles têm como características grandes lojas de baixo custo, pequena margem de lucro, elevado volume e auto-serviço, que oferecem preponderantemente uma ampla variedade de produtos alimentícios, produtos de limpeza e de uso doméstico.

Outra característica das grandes redes é que em geral elas operam com diferentes bandeiras (nome fantasia). Consistente com a teoria de Porter (1986), para cada uma das bandeiras as redes utilizam estratégias diferenciadas, visando atrair e 
Custos logísticos: mensuração e uso por redes supermercadistas do Estado do Rio Grande do Sul Marcos Antonio Souza, Rodrigo Machado Correa, Gustavo Pires Kruger

satisfazer às necessidades de diferentes parcelas da população. Conforme destacam Becco e Nunes (2003) e Werner e Segre (2008), é perfeitamente coerente, por exemplo, que uma mesma cadeia tenha lojas onde predominam nas prateleiras produtos populares e, ao mesmo tempo, sob outra bandeira, lojas voltadas para as classes $A / B$, oferecendo um volume maior de produtos sofisticados. O caso do Grupo Pão de Açúcar, com as bandeiras Extra Hipermercado, Lojas Assai e Extra-Perto é um exemplo. Outras redes também têm adotado tal estratégia, tais como a Rede Carrefour (com as bandeiras Atacadão e Carrefour Bairro), a Rede Wal-Mart (bandeiras Maxxi, Todo Dia, Hiperbompreço) e da Rede Sendas (bandeira Mais em Conta).

Essas estratégias representam uma reversão do que ocorreu durante muitas décadas, quando os aspectos operacionais relacionados à administração varejista foram negligenciados e as vastas e rentáveis possibilidades oferecidas pelo mercado financeiro permitiam que as empresas do setor compensassem com grande facilidade seus problemas operacionais (BLECHER, 2001). Fávero, Belfiore e De Ângelo (2005), ratificam tal entendimento, enfatizando que a estabilidade econômica, e por via de consequência a perda das receitas financeiras que eram propiciadas pelos elevados juros em conseqüência dos índices inflacionários, alterou significativamente a forma de atuação de grupos varejistas e reestruturou o mercado de consumo. A nova realidade econômica, aliada ao avanço tecnológico, à globalização e ao surgimento de novos formatos, alterou significativamente a forma de operação do varejo, abrindo espaço para questionamentos e aprimoramento do seu gerenciamento.

Além do fim de um acelerado processo inflacionário, uma das mudanças mais marcantes ocorridas no setor, e fruto da abertura e globalização de mercados, foi a transformação das redes em agentes globais de negócios. Coe et al. (2003 apud SOUZA; ALMEIDA, 2007), retratam a representatividade do varejo supermercadista globalizado, mensurado a valores expressos em USD bilhões (Tabela 1). 
Custos logísticos: mensuração e uso por redes supermercadistas do Estado do Rio Grande do Sul Marcos Antonio Souza, Rodrigo Machado Correa, Gustavo Pires Kruger

Tabela 1 - Faturamento do Varejo Mundial

\begin{tabular}{|c|c|c|c|c|c|}
\hline Empresa & $\begin{array}{l}\text { País de } \\
\text { Origem }\end{array}$ & $\begin{array}{c}\text { Receita } \\
\text { Total }\end{array}$ & $\begin{array}{c}\text { Receita } \\
\text { Internacional }\end{array}$ & $\begin{array}{l}\% \text { da Receita } \\
\text { Internacional }\end{array}$ & $\begin{array}{c}\text { № Países } \\
\text { em } \\
\text { que Opera }\end{array}$ \\
\hline Wal-Mart & $\begin{array}{l}\text { Estados } \\
\text { Unidos }\end{array}$ & 240,7 & 53,6 & 23,4 & 11 \\
\hline Carrefour & França & 79,6 & 39,2 & 49,2 & 32 \\
\hline Royal Ahold & Holanda & 63,3 & 53,3 & 84,2 & 27 \\
\hline Metro & Alemanha & 60,5 & 28,5 & 47,1 & 26 \\
\hline Tesco & Inglaterra & 50,3 & 10 & 19,9 & 12 \\
\hline Rewe & Alemanha & 44,3 & 12,7 & 28,7 & 12 \\
\hline Aldi & Alemanha & 41,0 & 15,2 & 37,1 & 12 \\
\hline Intermarche & França & 37,7 & 10,5 & 27,9 & 7 \\
\hline $\begin{array}{c}\text { Lidl \& } \\
\text { Schwarz }\end{array}$ & Alemanha & 33,4 & 11,3 & 33,8 & 16 \\
\hline Auchun & França & 32,4 & 13,8 & 42,6 & 15 \\
\hline Ito Yokado & Japão & 30,5 & 8,0 & 26,2 & 18 \\
\hline Tengelmann & Alemanha & 27,7 & 14,1 & 50,9 & 14 \\
\hline Delhaize & Bélgica & 22,9 & 18,3 & 79,9 & 10 \\
\hline
\end{tabular}

Fonte: Coe et al. (2003 apud SOUZA; ALMEIDA, 2007).

Xavier, Giuliani e Spers (2006) destacam que as fusões e aquisições entre as cinco maiores redes de supermercado do país mudaram o ranking nacional, com o fortalecimento das globalizadas. Segundo Parente (2000), estas grandes redes assumiram assim um posicionamento de varejo de massa. São empresas de grande porte e que operam em todo o território nacional, desenvolvendo sofisticados sistemas logísticos e de reposição contínua, e exercendo forte poder de barganha junto aos fornecedores. Ainda segundo Parente (2000), a estratégia adotada por esses supermercadistas atinge grandes volumes de vendas, com preços extremamente competitivos, direcionados para a grande massa de consumidores.

Parente (2000), no contexto do avanço da atividade supermercadista, esclarece que além das estratégias já referidas, e mais especificamente a respeito da maior eficiência na execução das atividades operacionais, são notórios os avanços possibilitados pelos desenvolvimentos tecnológicos. Cita, por exemplo, que após a implantação da informatização das frentes de caixas nos supermercados do Brasil na década de 1990, verificaram-se grandes transformações no melhor desempenho econômico das redes, simultaneamente ao melhor atendimento e satisfação do consumidor. Os avanços em TI, para Parente (2000), constituem o principal fator que 
Custos logísticos: mensuração e uso por redes supermercadistas do Estado do Rio Grande do Sul Marcos Antonio Souza, Rodrigo Machado Correa, Gustavo Pires Kruger

tem proporcionado a expansão dos negócios e as melhorias nos métodos de gestão e reduções de custos.

Outra ação gerencial direcionada à maior eficácia operacional, a menor custo, é a instalação de centros de distribuição (CD). Conforme esclarece Lavratti, Colossi e De Luca (2002), com a utilização de centros de distribuição a rede varejista recebe as mercadorias em apenas um local que vai servir a toda uma região. A existência de um CD significa que todos os estoques da rede se encontram consolidados em um único local, facilitando a aquisição e a alocação dos produtos. As unidades de venda têm a vantagem de poder solicitar somente as quantidades necessárias dos produtos a serem comercializados de acordo com a expectativa da próxima reposição. Isso se torna mais relevante, dado que, conforme enfatiza Lepsch (1996), o administrador supermercadista dispõe de limitado conhecimento sobre a situação da demanda futura do grande número de itens que comercializa, gerando com isso um elevado custo de oportunidade pela manutenção de estoques.

Os menores custos logísticos de movimentação e controle de estoques, bem como a manutenção de estoques em menor nível, são economias propiciadas pela existência de CD. Lavratti, Colossi e De Luca (2002) finalizam com a afirmativa de que a maximização dos benefícios propiciados pelos CD e pela eficaz gestão dos custos logísticos tem sido viabilizada pelos atuais recursos e ferramentas decorrentes da $\mathrm{TI}$.

Yoshizaki e Vidal (2007) abordam as questões de logística e custos logísticos nas redes de supermercados para frutas e hortaliças, discorrendo sobre a importância estratégica da logística para o alcance da sustentabilidade dos negócios. Para os autores, os centros e sistemas de distribuição são vitais para o segmento, principalmente para os produtos de curto ciclo de vida como ocorre com as frutas e hortaliças.

Silveira (2006) destaca que na Wal-Mart a redução dos custos logísticos é buscada por meio do incentivo à formação de grupos de produtores com compra garantida pelo supermercado. Conforme o autor, ao aperfeiçoar o uso da logística junto aos 14 fornecedores de perecíveis orgânicos, o Wal-Mart igualou os custos logísticos destes produtos com os convencionais. Para Santos (2006), a criação de um centro de 
Custos logísticos: mensuração e uso por redes supermercadistas do Estado do Rio Grande do Sul Marcos Antonio Souza, Rodrigo Machado Correa, Gustavo Pires Kruger

distribuição pode racionalizar os níveis de estoques contribuindo para a redução do custo logístico total, pois o estoque centralizado permite acompanhar melhor os níveis de estoque e controlar as necessidades de reabastecimento. Corroborando, Hill (2003 apud SANTOS, 2006, p.35) menciona que os fatores principais que levam ao uso dos centros de distribuição são basicamente: (1) redução do lead time; (2) desempenho nas entregas; (3) localização geográfica; (4) melhoria no nível de serviço; (5) redução dos custos logísticos; (6) aumento do market share; e (7) novo patamar de competitividade.

A viabilidade de se implantar avançados sistemas logísticos de gestão, como instrumento de alcance da eficiência e eficácia operacional, em busca da competitividade, passou a ser factível a partir do desenvolvimento da tecnologia de informação. Os estudos de Cooke (2006), Ferreira e Alves (2005) e Pires (2004) contribuem com o esclarecimento dessa questão. A gestão integrada de informações realizada entre os agentes internos e externos participantes do processo, mediante uso de ferramentas disponibilizadas pelo eletronic data interchange - EDI, por meio do qual é possível concretizar-se a gestão colaborativa na cadeia de suprimentos, talvez seja o principal desenvolvimento nessa área de tecnologia de informação.

A tecnologia da informação proporcionou para o gestor supermercadista a possibilidade de gerenciamento das atividades de apoio, o que antes era considerado praticamente impossível, visto que não existia um controle eficaz das receitas e custos oriundos dos diversos e complexos processos de apoio desse ramo, pois não possuíam um sistema informatizado. A partir disso, entende-se que a identificação e avaliação das atividades logísticas, assim como o gerenciamento dos custos logísticos dessas organizações, tornaram-se ações relevantes para a alavancagem de resultados.

\section{PROCEDIMENTOS METODOLÓGICOS}

\subsection{Classificação da Pesquisa}

Este estudo, na dimensão de seu objetivo, classifica-se como um estudo exploratório, pois de acordo com Rampazzo (1998), possibilita ao investigador ampliar sua experiência em relação a determinado problema, neste caso a gestão de custos 
Custos logísticos: mensuração e uso por redes supermercadistas do Estado do Rio Grande do Sul Marcos Antonio Souza, Rodrigo Machado Correa, Gustavo Pires Kruger

logísticos no segmento supermercadista. Segundo Vergara (2003), a investigação exploratória é realizada em área na qual há pouco conhecimento acumulado e sistematizado que, por sua natureza de sondagem, poderá indicar o surgimento de hipóteses passíveis de serem explorados em estudos posteriores.

Quanto à abordagem do problema, segundo Gil (1999), o estudo é qualitativo, pois não são utilizadas técnicas estatísticas na elucidação da problemática. Nas pesquisas qualitativas, segundo Silva e Menezes (2001), o ambiente natural é a fonte direta para a coleta de dados, e o pesquisador é o instrumento-chave, o qual tende a analisar seus dados indutivamente. Também é possível, com base em Boaventura (2004), enquadrar esta pesquisa com descritiva, uma vez que ela está direcionada a identificar e descrever as características de determinada população ou fenômeno, como é o objetivo deste estudo.

Por fim, e baseado em Yin (2001), a pesquisa também se enquadra como um estudo múltiplo de casos, tendo em vista que se coloca uma questão do tipo "como", não há controle sobre os eventos pesquisados e está sendo tratado um fenômeno inserido no contexto da vida real das organizações pesquisadas. Outra característica dessa estratégia de estudo de caso, também fundamentado em Yin (2001), é a adoção de várias fontes de evidências, ou seja, as entrevistas, a observação direta possibilitada pela presença física nas empresas e a consulta a registros e relatórios liberados pelos gestores. A sua classificação complementar de um estudo exploratório e descritivo também é uma característica de estudos de caso, conforme enfatizado por Yin (2001).

\subsection{Processo de Coleta dos Dados}

A coleta de dados deu-se por meio de entrevista pessoal, utilizando-se para tanto um questionário direcionador, estruturado com perguntas abertas. O período de realização das entrevistas compreendeu os meses de junho a agosto de 2009.

Dado o foco de investigar a gestão dos custos logísticos das empresas, optou-se por entrevistar profissionais com atuação na área de contabilidade de custos ou controladoria. 
Custos logísticos: mensuração e uso por redes supermercadistas do Estado do Rio Grande do Sul Marcos Antonio Souza, Rodrigo Machado Correa, Gustavo Pires Kruger

As entrevistas foram realizadas na sede de três redes de supermercados varejistas de porte médio, localizadas no estado do Rio Grande do Sul. Duas das redes localizam-se na fronteira oeste do Estado, enquanto a terceira se encontra instalada na região metropolitana de Porto Alegre.

\subsection{Processo de Tratamento e Análise dos Dados}

A tabulação e análise dos dados pesquisados foi processada mediante uso do software Microsoft Excel®. Aliado a isso foi processada a leitura crítica do conteúdo das entrevistas a fim de compreender a realidade e os processos adotados em cada uma das redes.

A par dos resumos qualitativos, os dados foram reunidos e apresentados na forma de tabelas, de modo a identificá-los de maneira mais objetiva. Isso é referendado por Calvo (2004), para o qual a tabela é um quadro que resume um conjunto de observações, cujo objetivo é o de produzir uma impressão mais rápida e viva do fenômeno em estudo.

Além da análise comparativa dos dados referentes a cada uma das redes, apresenta-se ao final uma visão global do conjunto das redes pesquisadas.

\section{APRESENTAÇÃO E ANÁLISE DOS DADOS}

\subsection{Informações Gerais das Empresas Pesquisadas}

Conforme descrito anteriormente, o estudo buscou compreender, além do grau de relevância que redes supermercadistas do Rio Grande do Sul estão dando para os custos logísticos, quais as ferramentas que essas organizações estão utilizando para a correta mensuração dessas atividades. O Quadro 3 apresenta uma breve caracterização dos entrevistados. 
Custos logísticos: mensuração e uso por redes supermercadistas do Estado do Rio Grande do Sul Marcos Antonio Souza, Rodrigo Machado Correa, Gustavo Pires Kruger

\begin{tabular}{|c|c|c|c|}
\hline Dados & Rede A & Rede B & Rede C \\
\hline $\begin{array}{c}\text { Tempo de atuação na } \\
\text { empresa }\end{array}$ & 17 anos & 14 anos & Controller \\
\hline Cargo atual ocupado & $\begin{array}{c}\text { Sócio-gerente } \\
\text { e fundador }\end{array}$ & Contador & 1 ano \\
\hline Tempo no cargo na empresa & 17 anos & 14 anos & 1 ano \\
\hline $\begin{array}{c}\text { Tempo no cargo incluindo } \\
\text { outras empresas. }\end{array}$ & 23 & 32 anos & $\begin{array}{c}\text { Ensino Superior - } \\
\text { Especialização MBA }\end{array}$ \\
\hline Escolaridade & Ensino médio & $\begin{array}{c}\text { Ensino Superior - } \\
\text { Graduação }\end{array}$ & \\
\hline
\end{tabular}

Quadro 3: Perfil Geral dos Entrevistados

Nota-se pelas referências do Quadro 3 que todos os entrevistados estão há mais de uma década na empresa, o que sinaliza forte experiência no segmento e conhecimento da empresa. Outro indicador é o nível de escolaridade superior dos entrevistados, com exceção do representante da Rede $A$, que em compensação é o sócio-gerente fundador da empresa, um empreendedor há mais de 20 anos nesse tipo de negócio. O entrevistado da Rede B possui graduação em Ciências Contábeis, enquanto o da Rede $\mathrm{C}$ é especialista em gestão empresarial.

As principais características das empresas estão apresentadas no Quadro 4. São redes supermercadistas de pequeno e médio porte, considerando-se o parâmetro quantidade de Checkouts adotado pelo BNDES (1996) para esse tipo de classificação.

\begin{tabular}{|c|c|}
\hline Portes & $\begin{array}{c}\text { Quantidade de } \\
\text { Checkouts }\end{array}$ \\
\hline Pequeno & Até 4 \\
\hline Pequeno/Médio & $5-9$ \\
\hline Médio & $10-19$ \\
\hline Grande & $20-49$ \\
\hline Hipermercado & 50 ou mais \\
\hline
\end{tabular}

Quadro 4: Classificação dos Portes de Supermercados Fonte: BNDES (1996).

O Quadro 5, apresentado na sequência, contém uma síntese das características das redes supermercadistas pesquisadas. 
Custos logísticos: mensuração e uso por redes supermercadistas do Estado do Rio Grande do Sul Marcos Antonio Souza, Rodrigo Machado Correa, Gustavo Pires Kruger

\begin{tabular}{|c|c|c|c|}
\hline Características & Rede A & Rede B & Rede C \\
\hline Quantidade de lojas & 4 & 5 & 12 \\
\hline Municípios atendidos & 1 & 1 & 6 \\
\hline Quantidade total de check-outs & 48 & 78 & 9 \\
\hline $\begin{array}{c}\text { Quantidade média de check- } \\
\text { outs por loja }\end{array}$ & 12 & 15,6 & 704 \\
\hline $\begin{array}{c}\text { Quantidade de funcionários } \\
\begin{array}{c}\text { Quantidade média de } \\
\text { funcionários } \\
\text { por loja }\end{array}\end{array}$ & 176 & 421 & De 100 a 125 \\
\hline $\begin{array}{c}\text { Faturamento anual (R\$ } \\
\text { milhões) }\end{array}$ & De 26 a 50 & De 76 a 100 & 1994 \\
\hline Ano de fundação & 1982 & 1995 & Mista \\
\hline $\begin{array}{c}\text { Formato da Gestão: } \\
\text { profissionalizada ou familiar }\end{array}$ & Predominância & Predominância \\
\hline $\begin{array}{c}\text { Nível de autonomia dos } \\
\text { gerentes }\end{array}$ & Baixo & Bamiliar & Médio \\
\hline
\end{tabular}

Quadro 5: Síntese das Características das Redes Pesquisadas

Observa-se que a Rede C apresenta indicadores mais robustos em quantidade de lojas, municípios atendidos, quantidade de funcionários e faturamento anual. Quanto ao formato de gestão, ao contrário das redes $A$ e $B$, constata-se a incidência de uma gestão mista na rede $\mathrm{C}$, ou seja, têm-se a gestão familiar aliada à profissional, consistente com o que é mais presente nesse porte de empresa. A maior quantidade média de funcionários da Rede $\mathrm{B}$ deve-se majoritariamente à maior quantidade média de check-outs por loja. Identificou-se o baixo nível de autonomia dos gerentes de lojas das Redes A e B, tendo em vista que eles atuam somente sobre aspectos operacionais e específicos das respectivas lojas, subordinados às orientações da gerência geral. $\mathrm{Na}$ Rede C a informação é de existência de autonomia média. Apesar de não exemplificado, foi confirmado pelo respondente que os gerentes de loja participam de alguns direcionamentos estratégicos.

As principais características do posicionamento estratégico das redes estão apresentadas no Quadro 6. 
Custos logísticos: mensuração e uso por redes supermercadistas do Estado do Rio Grande do Sul Marcos Antonio Souza, Rodrigo Machado Correa, Gustavo Pires Kruger

\begin{tabular}{|c|c|c|c|}
\hline Características & Rede A & Rede B & Rede C \\
\hline Perfil dos clientes-alvo & Classe média & Classe média & $\begin{array}{c}\text { Classe média e } \\
\text { alta }\end{array}$ \\
\hline Nível de concorrência & Alto & Alto & Alto \\
\hline Estratégia competitiva adotada & Custo & Custo & $\begin{array}{c}\text { Custo e } \\
\text { Diferenciação }\end{array}$ \\
\hline $\begin{array}{c}\text { Existência algum mapa com os } \\
\text { objetivos estratégicos da rede }\end{array}$ & $\begin{array}{c}\text { Não, apenas } \\
\text { alguns indicadores }\end{array}$ & Sim, parcialmente & $\begin{array}{c}\text { Sim, mais } \\
\text { abrangente }\end{array}$ \\
\hline
\end{tabular}

Quadro 6: Características Estratégicas das Redes

Quanto ao perfil dos clientes, no que se refere ao poder aquisitivo, os respondentes das Redes A e B classificam-nas como fornecedoras de produtos para a classe média, enquanto que a Rede $\mathrm{C}$, com atuação mais abrangente, alcança também a classe alta.

Ratificando o perfil do setor já retratado em seções anteriores, tanto o nível de concorrência quanto a intensidade de avaliação de desempenho, são aspectos que os gestores das três redes consideraram como elevado, visto que no mercado em que as redes pesquisadas atuam há a presença de concorrentes globais. A dificuldade para fixação e majoração de preços é uma característica de mercado enfatizada pelos três respondentes.

A estratégia adotada pelas organizações A e B é a liderança em custos, o que significa a existência de esforço em oferecer aos clientes um valor melhor ou igual àquele oferecido pelos concorrentes. Mesmo na Rede $\mathrm{C}$, que declara adotar como estratégia a diferenciação, pelo menos para produtos direcionados a clientes de alta faixa de renda, o respondente destaca a necessidade de observar com cuidado os preços da concorrência para produtos e serviços semelhantes ou substitutos.

O delineamento e apresentação de um mapa estratégico, nos moldes da configuração do BSC, não parece ser uma preocupação da gestão das redes pesquisadas. $O$ respondente da Rede $A$ informa que há apenas a adoção de alguns indicadores, mais caracterizados como referências da reclamação de clientes e, em algumas situações, mapeamento de sugestões desses clientes. O respondendo da Rede B declara a utilização de uma maior gama de indicadores, sem, entretanto, especificá-los. Na Rede C, aparentemente a melhor estruturada, o respondente sinaliza 
Custos logísticos: mensuração e uso por redes supermercadistas do Estado do Rio Grande do Sul Marcos Antonio Souza, Rodrigo Machado Correa, Gustavo Pires Kruger

que há um direcionamento estratégico mais robusto, contando inclusive com a participação, mesmo que parcial, dos gerentes das lojas. Mesmo não sendo com toda amplitude, o respondente afirma existir um BSC parcial.

Tendo em vista o objetivo deste estudo, considerou-se importante identificar alguns indicadores da estrutura organizacional adotada pelas redes na área contábil, conforme apresentado no Quadro 7.

\begin{tabular}{|c|c|c|}
\hline Características do Departamento Contábil & Rede B & Rede C \\
\hline Contabilidade interna ou externa & $\begin{array}{c}\text { Externa p/fins fiscais e } \\
\text { interna p/fins gerenciais }\end{array}$ & $\begin{array}{c}\text { Interna para ambas as } \\
\text { finalidades }\end{array}$ \\
\hline Quantidade de funcionários & 9 & $\begin{array}{c}\text { 20 (inclusive para a } \\
\text { Controladoria) }\end{array}$ \\
\hline $\begin{array}{c}\text { Intensidade da avaliação de desempenho das } \\
\text { gerências }\end{array}$ & Alta & Sim \\
\hline $\begin{array}{c}\text { Compartisthamento do setor controladoria } \\
\text { entre as lojas e outros departamentos }\end{array}$ & $\begin{array}{c}\text { Sim, informações } \\
\text { limitadas pela intranet }\end{array}$ & $\begin{array}{c}\text { Sim, informações } \\
\text { limitadas pela intranet }\end{array}$ \\
\hline $\begin{array}{c}\text { O contador dedica-se exclusivamente à } \\
\text { organização }\end{array}$ & $\begin{array}{c}\text { Sim, no escritório } \\
\text { contratado há um } \\
\text { específico para a Rede }\end{array}$ & $\begin{array}{c}\text { Sim, funcionário da } \\
\text { própria empresa }\end{array}$ \\
\hline $\begin{array}{c}\text { Software utilizado pelo departamento de } \\
\text { contabilidade é próprio ou terceirizado } \\
\text { (licenciado) }\end{array}$ & $\begin{array}{c}\text { Terceirizado: uso sob } \\
\text { licenciamento }\end{array}$ & $\begin{array}{c}\text { Desenvolvimento } \\
\text { Próprio }\end{array}$ \\
\hline $\begin{array}{c}\text { Possibilidade do sistema contábil em identificar } \\
\text { atividades e custos logísticos }\end{array}$ & Não há & Não há \\
\hline $\begin{array}{c}\text { Tecnologia utilizada (EDI, INTERNET, } \\
\text { INTRANET ou outras) }\end{array}$ & Intranet & Internet \\
\hline $\begin{array}{c}\text { Existência de um CPD (centro de processamento } \\
\text { de dados) }\end{array}$ & Sim: pequena estrutura & $\begin{array}{c}\text { Sim, mas com estrutura } \\
\text { apenas mediana }\end{array}$ \\
\hline
\end{tabular}

Quadro 7: Estrutura Contábil das Redes

A rede $A$ não possui estrutura departamental contábil, daí a sua exclusão do Quadro 7. Essa estrutura contábil de escritório externo normalmente está concentrada no cumprimento de exigências fiscais, o que dificulta significativamente a correta mensuração dos custos logísticos, bem como a geração de outras informações de natureza financeira e econômica. As redes B e C, apesar de limitações, possuem um departamento específico para a realização do processo contábil. Nota-se, entretanto, somente a rede $\mathrm{C}$ utiliza a função de controladoria para o planejamento, execução e controle das atividades operacionais. 
Custos logísticos: mensuração e uso por redes supermercadistas do Estado do Rio Grande do Sul Marcos Antonio Souza, Rodrigo Machado Correa, Gustavo Pires Kruger

Quanto aos demais recursos da estrutura de tecnologia de informação há fortes indicações da necessidade de acentuados avanços. O uso limitado de intranet, ausência de outros recursos de maior potência e as limitações de um CPD apenas operacional foi indicado pelos respondentes de ambas as Redes B e C. Mesmo com as limitações, novamente constata-se a melhor estrutura gerencial da Rede C.

Especificamente quanto às condições para mensuração dos custos logísticos, nota-se que em ambas há fortes restrições do sistema contábil em identificar as atividades logísticas e os custos correspondentes.

Em conclusão a essa primeira parte da pesquisa, direcionada à identificação das condições operacionais das redes pesquisadas, apresenta-se no Quadro 8 as características físicas da estrutura de estocagem e distribuição adotada pelas redes.

\begin{tabular}{|c|c|c|c|}
\hline Pergunta & Rede A & Rede B & Rede C \\
\hline $\begin{array}{c}\text { Existência de Centro } \\
\text { de distribuição }\end{array}$ & $\begin{array}{c}\text { Sim, apenas uma } \\
\text { unidade }\end{array}$ & $\begin{array}{c}\text { Não utiliza e não há } \\
\text { planos para isso }\end{array}$ & $\begin{array}{c}\text { Sim, apenas uma } \\
\text { unidade }\end{array}$ \\
\hline $\begin{array}{c}\text { Situação dos CD's } \\
\text { (próprios ou alugados) }\end{array}$ & Próprio & - & Próprio \\
\hline $\begin{array}{c}\text { Existência em todas as } \\
\text { lojas de um local } \\
\text { adequado para a } \\
\text { estocagem de } \\
\text { produtos }\end{array}$ & $\begin{array}{c}\text { Sim, suficiente para } \\
\text { um tempo reduzido }\end{array}$ & $\begin{array}{c}\text { Sim, suficiente para } \\
\text { aguardar reposições } \\
\text { pelos fornecedores }\end{array}$ & $\begin{array}{c}\text { Sim, suficiente para } \\
\text { um tempo reduzido }\end{array}$ \\
\hline $\begin{array}{c}\text { Situação das lojas } \\
\text { próprias ou alugadas) }\end{array}$ & $\begin{array}{c}\text { 3 Próprias e uma } \\
\text { alugada. }\end{array}$ & Alugadas & Próprias \\
\hline
\end{tabular}

Quadro 8: Características Físicas de Estocagem: Centro de Distribuição e Lojas

Com o objetivo de investigar a potencial origem do custo logístico de armazenagem e movimentação interna perguntou-se aos entrevistados sobre a existência de algum centro de distribuição e sobre a existência de espaço nas lojas para fins de estocagem. Conforme já tratado no referencial teórico, é sabido que essas duas áreas (CD e estocagem em lojas) são indicadores representativos da ocorrência de custo logístico no comércio varejista.

Conforme é possível verificar pelas respostas resumidas no Quadro 8, a Rede B não possui $C D$ e nem tem planos para tal. As Redes $A$ e $C$ utilizam tal recurso como parte da estrutura de abastecimento das lojas, além de contarem com espaço 
Custos logísticos: mensuração e uso por redes supermercadistas do Estado do Rio Grande do Sul Marcos Antonio Souza, Rodrigo Machado Correa, Gustavo Pires Kruger

adequado para estoques transitórios (entre 7 de 15 dias) nas lojas. Esse espaço também é disponível na Rede $B$, suficiente para um tempo superior ao declarado pelas duas outras redes, apesar de não especificado pelo respondente. Ainda quanto às lojas, a Rede $C$ revela maior patrimônio, pois todas elas são próprias, o que não ocorre na Rede B e apenas parcialmente se verifica na Rede A.

Adicionalmente constatou-se que todas as redes possuem frota própria de veículos leves e pesados. Essa frota é utilizada para a busca de determinados abastecimentos e para entrega de compras (denominadas pelos entrevistados de 'rancho'). Todas elas fazem essas entregas sem custo adicional para os clientes. Para alguns recebimentos, como os de produtos hortifrutigranjeiros, as três redes utilizam um sistema de distribuição análogo ao sistema Milk Run, originário da indústria automobilística. Nesse sistema, os produtos são colhidos na Central de Abastecimento do Rio Grande do Sul S.A. - CEASA/RS - e distribuídos em todas as lojas da rede por um único veículo, mitigando custos com transporte e tempo na realização da operação.

A logística reversa revelou-se utilizada pelas redes pesquisadas, mesmo que não conhecida por eles com essa denominação. Os principais processos utilizados no fluxo reverso são: retorno de produtos com validade expirada, bem como problemas de qualidade do produto, retorno de produtos em consignação, embalagens para reciclagens, entre outros.

Outra característica das redes analisadas é que nenhuma delas utiliza operadores logísticos, ou seja, todas as atividades logísticas são realizadas internamente pelas entidades. Também é importante destacar que não ocorre a integração com outras redes, formando parcerias para as compra em conjunto economia de escala - o que poderia contribuir com a redução dos custos da cadeia. Ao invés de parcerias estratégicas para o suprimento de mercadorias as compras são analisadas a cada pedido de forma individual pelas redes.

Após identificar os aspectos operacionais mais relevantes em relação à ocorrência e controle dos custos logísticos, apresentam-se na sequência as questões mais diretamente relacionadas à mensuração desses custos. 
Custos logísticos: mensuração e uso por redes supermercadistas do Estado do Rio Grande do Sul Marcos Antonio Souza, Rodrigo Machado Correa, Gustavo Pires Kruger

\subsection{Mensuração e Relevância dos Custos Logísticos}

Dada a importância da mensuração dos custos logísticos para o planejamento e controle das operações, torna-se necessária a departamentalização, o que implica na criação de um setor específico para a gestão concentrada dessas atividades. De acordo com as respostas obtidas, identificou-se que as Redes A e B, segundo os gestores, possuem um setor para realizar esse processo, enquanto que a Rede $C$ não o possui, mas pretende adotá-lo no futuro. Entretanto, em questionamentos complementares verificou-se que o setor ao qual os administradores se referiram trata apenas do controle físico de entrada e saída de mercadorias. Portanto, muito distante do mínimo recomendado pela literatura da área.

Outro aspecto relevante quanto a mensuração desses custos, é a utilização de um adequado método de custeio. Essas e outras questões quanto à mensuração dos custos logísticos estão resumidas no Quadro 9.

\begin{tabular}{|c|c|c|c|}
\hline Pergunta & Rede A & Rede B & Rede C \\
\hline $\begin{array}{c}\text { Identificação contábil das } \\
\text { atividades logísticas }\end{array}$ & $\begin{array}{c}\text { Não, o sistema não } \\
\text { é estruturado para } \\
\text { isso }\end{array}$ & $\begin{array}{c}\text { Não, o sistema não é } \\
\text { estruturado para isso }\end{array}$ & $\begin{array}{c}\text { Sim, o sistema é } \\
\text { parcialmente } \\
\text { estruturado para } \\
\text { isso }\end{array}$ \\
\hline $\begin{array}{c}\text { Utilização de algum método de } \\
\text { custeio para mensurar os } \\
\text { custos logísticos }\end{array}$ & Não mensura & Não mensura & $\begin{array}{c}\text { Sim, utiliza apenas } \\
\text { parcialmente }\end{array}$ \\
\hline $\begin{array}{c}\text { Forma adotada para mensurar } \\
\text { os custos logísticos }\end{array}$ & $\begin{array}{c}\text { Apenas em } \\
\text { relatórios extra } \\
\text { contábeis }\end{array}$ & $\begin{array}{c}\text { Apenas em relatórios } \\
\text { extra contábeis }\end{array}$ & $\begin{array}{c}\text { Utiliza parcialmente } \\
\text { o Custeio ABC }\end{array}$ \\
\hline $\begin{array}{c}\text { Existência de algum software } \\
\text { específico para mensurar } \\
\text { custos logísticos }\end{array}$ & Não há & Não há & Não há \\
\hline $\begin{array}{c}\text { Adoção de relatórios } \\
\text { gerenciais para } \\
\text { acompanhamento do } \\
\text { planejamento, controle e } \\
\text { análise dos custos logísticos }\end{array}$ & Não adota & Não adota & parcialmente \\
\hline $\begin{array}{c}\text { Existência de plano de contas } \\
\text { contábil detalhado por tipo de } \\
\text { custos logísticos }\end{array}$ & Não há & Não há & Apenas \\
\hline $\begin{array}{c}\text { Programação de adoção do } \\
\text { plano de contas mais } \\
\text { detalhado }\end{array}$ & No momento não & No momento não & No momento não \\
\hline $\begin{array}{c}\text { Compartilha de informações } \\
\text { via Tl (estoques, demandas, } \\
\text { etc.) com algum ou alguns } \\
\text { fornecedores }\end{array}$ & Não compartilha & Não compartilha & Não compartilha \\
\hline
\end{tabular}


Custos logísticos: mensuração e uso por redes supermercadistas do Estado do Rio Grande do Sul Marcos Antonio Souza, Rodrigo Machado Correa, Gustavo Pires Kruger

\begin{tabular}{|c|c|c|c|}
\hline $\begin{array}{c}\text { Tem conhecimento das } \\
\text { ferramentas de custeio ABC, } \\
\text { TCO, CPA e DPP }\end{array}$ & $\begin{array}{c}\text { Sim, apenas o ABC, } \\
\text { mas não adota }\end{array}$ & $\begin{array}{c}\text { Sim, apenas o ABC, } \\
\text { mas não adota }\end{array}$ & $\begin{array}{c}\text { Sim - ABC, CPA, } \\
\text { DPP - mas apenas } \\
\text { adota parcialmente } \\
\text { o ABC }\end{array}$ \\
\hline $\begin{array}{c}\text { Se não adota, informar plano } \\
\text { de adoção futura }\end{array}$ & $\begin{array}{c}\text { Pretende adotar } \\
\text { ABC, mas não há } \\
\text { prazo }\end{array}$ & $\begin{array}{c}\text { Pretende adotar } \\
\text { ABC, mas não há } \\
\text { prazo }\end{array}$ & $\begin{array}{c}\text { Não pretende } \\
\text { adotar outras. } \\
\text { Talvez melhorar o } \\
\text { ABC }\end{array}$ \\
\hline $\begin{array}{c}\text { Causas principais da não } \\
\text { adoção }\end{array}$ & $\begin{array}{c}\text { Não é prioritário, } \\
\text { pois envolve mais } \\
\text { custos }\end{array}$ & $\begin{array}{c}\text { Não é prioritário, pois } \\
\text { envolve mais custos }\end{array}$ & $\begin{array}{c}\text { Não é prioritário, } \\
\text { pois envolve mais } \\
\text { custos }\end{array}$ \\
\hline
\end{tabular}

Quadro 9: Aspectos Sobre a Mensuração dos Custos Logísticos

A única Rede que parcialmente possui um sistema de custeio que permite uma mensuração aproximada desses custos é a Rede C. Com relação às demais, mesmo essa adoção parcial ainda está longe de ser uma realidade. Na verdade, nem planos há a respeito.

Mediante questões adicionais procurou-se avançar nas causas que limitam a adoção de instrumentos mais adequados de gestão dos custos logísticos, mesmo que parcialmente. As respostas a tais questões, dadas pelos três entrevistados, resumemse na preocupação maior pela contenção de novos custos. Nota-se, aqui, a prevalência de gestão do curto prazo, com forte ausência de visão das possíveis consequências no longo prazo.

Os elementos finais da entrevista evidenciam o grau de importância que a direção dá ao planejamento e controle dos custos logísticos. Obteve-se como resposta unânime uma alta relevância, já que representa um percentual próximo à margem líquida da Rede (Quadro 10). 
Custos logísticos: mensuração e uso por redes supermercadistas do Estado do Rio Grande do Sul Marcos Antonio Souza, Rodrigo Machado Correa, Gustavo Pires Kruger

\begin{tabular}{|c|c|c|c|}
\hline Pergunta & Rede A & Rede B & Rede C \\
\hline $\begin{array}{c}\text { Utilização de indicadores não } \\
\text { financeiros para medição do } \\
\text { desempenho das atividades logísticas }\end{array}$ & $\begin{array}{c}\text { Apenas } \\
\text { parcialmente }\end{array}$ & $\begin{array}{c}\text { Apenas } \\
\text { parcialmente }\end{array}$ & $\begin{array}{c}\text { Apenas } \\
\text { parcialmente }\end{array}$ \\
\hline $\begin{array}{l}\text { Processo que mais gera custos } \\
\text { logísticos para a rede - entrada de } \\
\text { mercadorias, movimentação de } \\
\text { mercadorias ou saída de mercadorias }\end{array}$ & $\begin{array}{l}\text { Suprimento: } \\
\text { aquisição e } \\
\text { recebimento }\end{array}$ & $\begin{array}{c}\text { Interno: } \\
\text { movimentação } \\
\text { interna e } \\
\text { estocagem }\end{array}$ & $\begin{array}{c}\text { Interno: } \\
\text { movimentação } \\
\text { interna e } \\
\text { estocagem } \\
\end{array}$ \\
\hline $\begin{array}{l}\text { A tecnologia da informação é } \\
\text { considerada como fundamental para a } \\
\text { apuração dos custos logísticos }\end{array}$ & $\begin{array}{l}\text { Sim, mas não há } \\
\text { investimentos para } \\
\text { implantá-las }\end{array}$ & $\begin{array}{l}\text { Sim, mas não há } \\
\text { investimentos } \\
\text { para implantá-las }\end{array}$ & $\begin{array}{l}\text { Sim, mas não há } \\
\text { investimentos } \\
\text { para implantá- } \\
\text { las }\end{array}$ \\
\hline $\begin{array}{l}\text { Elementos de custo logísticos mais } \\
\text { significativos para a organização }\end{array}$ & $\begin{array}{l}\text { Os relacionados ao } \\
\text { transp. } \mathrm{E} \\
\text { recebimento de } \\
\text { mercadorias }\end{array}$ & $\begin{array}{l}\text { Os relacionados } \\
\text { à armazenagem } \\
\text { e movimentação }\end{array}$ & $\begin{array}{l}\text { Os relacionados } \\
\text { à armazenagem } \\
\text { e movimentação }\end{array}$ \\
\hline $\begin{array}{l}\text { Representatividade dos custos } \\
\text { logísticos no custo total da rede }\end{array}$ & Elevada & Elevada & Elevada \\
\hline $\begin{array}{l}\text { Importância da mensuração dos custos } \\
\text { logísticos }\end{array}$ & Elevada & Elevada & Elevada \\
\hline $\begin{array}{l}\text { Participação relativa (\%) do custo } \\
\text { logístico em relação ao custo total da } \\
\text { rede }\end{array}$ & Estimado em 5\% & Estimado em $4 \%$ & $\begin{array}{l}\text { Estimado em } \\
\qquad 3 \%\end{array}$ \\
\hline $\begin{array}{c}\text { Existência de orçamento dos custos } \\
\text { logísticos }\end{array}$ & $\begin{array}{l}\text { Não há efetivo } \\
\text { planejamento e } \\
\text { controle destes } \\
\text { custos }\end{array}$ & $\begin{array}{l}\text { Não há efetivo } \\
\text { planejamento e } \\
\text { controle destes } \\
\text { custos }\end{array}$ & $\begin{array}{l}\text { Não há efetivo } \\
\text { planejamento e } \\
\text { controle destes } \\
\text { custos }\end{array}$ \\
\hline $\begin{array}{l}\text { Importância dada pela direção da } \\
\text { empresa ao planejamento e controle } \\
\text { dos custos logísticos }\end{array}$ & $\begin{array}{c}\text { Alta, apesar de não } \\
\text { utilizar }\end{array}$ & $\begin{array}{l}\text { Alta, apesar de } \\
\text { não utilizar }\end{array}$ & $\begin{array}{l}\text { Alta, apesar de } \\
\text { não utilizar }\end{array}$ \\
\hline
\end{tabular}

Quadro 10: Aspectos Sobre a Relevância dos Custos logísticos

Os dados consolidados no Quadro 10 indicam, na ótica dos respondentes, que a adoção de relatórios extra-contábeis parciais mais concentrados em alguns poucos indicadores não-financeiros, tem atendido minimamente as informações para a gestão.

Mesmo não havendo uma mensuração dos custos logísticos, para o respondente da Rede A as atividades de suprimento, representadas pela aquisição e recebimento, constituem a parte mais onerosa do processo logístico. Já para os entrevistados das Redes B e C, é o processo interno (movimentação interna e estocagem) o mais oneroso. Essa percepção, derivada do uso de indicadores não-financeiros servem, pelo menos, para direcionar ações na gestão dessas atividades visando executá-las de forma mais eficiente e eficaz. Mesmo que não visível aos gestores, essa é uma decorrência da adoção do ABM - activity based management. 
Custos logísticos: mensuração e uso por redes supermercadistas do Estado do Rio Grande do Sul Marcos Antonio Souza, Rodrigo Machado Correa, Gustavo Pires Kruger

Apesar do reconhecimento da relevância dos custos logísticos e, consequentemente, da sua mensuração, é evidente a não atenção dada pela gestão das redes supermercadistas pesquisadas. O que a princípio parece ser uma inconsistência, é, na realidade, uma reafirmação da falta de disposição (ou de recursos) para novos investimentos nesse instrumento de gestão. Isso ficou perceptível nas respostas dadas pelos entrevistados, mesmo considerando a aparente maior preocupação da Rede $\mathrm{C}$.

A mesma interpretação pode ser dada à importância do uso de TI na gestão dos custos logísticos. De fato, apesar dos gestores considerarem a TI como fundamental para a apuração dos custos logísticos, o sistema utilizado pelas redes não suporta a demanda necessária para uma mensuração acurada desses custos. A esse respeito, cabe ressaltar o fato de que no centro de processamento de dados das Redes B e C sequer há um profissional com especialidade em programação, o que certamente prejudica o desenvolvimento de sistemas mais apropriados.

A respeito da representatividade dos custos logísticos, e mesmo não sendo perfeitamente comparáveis, parece haver uma subavaliação das redes pesquisadas a respeito dessa dimensão financeira, dada a informação disponibilizada pelo estudo de Fleury e Wanke (2003) de que os custos logísticos chegam a representar $7 \%$ do faturamento das indústrias brasileiras. Comparações mais efetivas somente poderão ser feitas a partir da mensuração e divulgação por supermercados varejistas como os aqui analisados.

\section{CONCLUSÕES}

Há uma farta literatura enfatizando que em um ambiente de forte concorrência e de uma rentabilidade cada vez mais reduzida, o gerenciamento dos custos logísticos passa a ser relevante para que as redes supermercadistas tenham informações úteis para melhor direcionar o processo de avaliação de desempenho e direcionamento de estratégias e ações corretivas. 
Custos logísticos: mensuração e uso por redes supermercadistas do Estado do Rio Grande do Sul Marcos Antonio Souza, Rodrigo Machado Correa, Gustavo Pires Kruger

No âmbito dos três casos apresentados neste estudo, apesar da importância declarada pelos gestores entrevistados, as redes estudadas, com exceção de uma (Rede C), não estão mensurando os custos logísticos conforme sugere a literatura, utilizando para tanto os tradicionais relatórios contábeis para tal mensuração. De maneira inconsistente em relação à estratégia que busca a liderança em custos, as redes $A$ e $B$ não mensuram e não tem um efetivo sistema de controle dos custos logísticos. Destaca-se, entretanto, que mesmo na Rede C essa mensuração ocorre de forma muito superficial.

Outro aspecto que dificulta a mensuração dos custos logísticos nas Redes A e B é a ausência da alta direção no planejamento, execução e controle dessas atividades. Diante dos dados e informações coletadas durante a pesquisa é seguro argumentar de que não há expectativas, de curto e médio prazo, de que essa realidade venha a mudar significativamente.

Durante a execução das entrevistas, dadas as manifestações dos respondentes, é perceptível que a mudança dos procedimentos atuais está excluída das prioridades estabelecidas pela alta direção das redes pesquisadas.

Considerando-se o conteúdo da literatura pesquisada, sinalizando as estratégias de atuação das grandes redes, com bandeiras paralelas e ações mais focalizadas em mercados específicos, atualmente atendidos pelos supermercados de pequeno e médio porte, parece ser razoável concluir que as fraquezas gerenciais dessas redes menores poderão, no futuro, expô-las a uma forte ameaça à sua continuidade sustentável.

Apesar da confirmação dos resultados deste estudo, quando comparado com outros estudos semelhantes, como o de Laidens, Teles e Muller (2007), sugere-se que outros sejam realizados. Um dos focos de pesquisa recomendados é investigar em pequenas e médias redes de supermercados varejistas, a tendência que vem sendo verificada em seu desempenho nos últimos anos, em contraposição à forma e instrumentos adotados por elas no processo de gestão, estratégicos e operacionais, especialmente nas questões logísticas analisadas neste estudo. Acredita-se que novas descobertas nessa linha de pesquisa poderão descortinar e despertar novas 
Custos logísticos: mensuração e uso por redes supermercadistas do Estado do Rio Grande do Sul Marcos Antonio Souza, Rodrigo Machado Correa, Gustavo Pires Kruger

alternativas para a gestão das redes supermercadistas de pequeno e médio porte visando torná-las cada vez mais competitivas.

\section{REFERÊNCIAS}

BALlOU, R, H. (2001). Gerenciamento da Cadeia de Suprimentos: Planejamento, organização e Logística Empresarial. (4 ed.). Porto Alegre: Bookman.

BARSKY, Noah P.; ELLINGER, Alexander E. (2001). Unleashing in the value in the supply chain. Strategic Finance, v.82, n.7, p.32-37, jan.

BECCO, J.Eliseu; NUNES, F.R. Melo. (2003). A logística dos supermercados periféricos estudo de caso em Fortaleza com aplicação do benchmarking. In: ENCONTRO NACIONAL DE ENGENHARIA DE PRODUÇẪO - ENEGEP, XXIII. Anais... Ouro Preto, ENEGEP. CD-ROM.

BLECHER, N. (2001). Quer preço ou quer marca. Revista Exame, ano 35, n.12, p.32.

BNDES - BANCO NACIONAL DE DESENVOLVIMENTO ECONÔMICO E SOCIAL. (1996). Comercio varejista de supermercados. Rio de Janeiro. Disponível em: www.bndes.gov.br/conhecimento/relato/supmerca.pdf. Acesso em 22/out/2009.

BOAVENTURA, Edivaldo M. (2004). Metodologia Científica. São Paulo: Atlas.

BOWERSOX, D.J.; CLOSS, D.J.; STANK, T.P.; KELLER, S.B. (2000). How supply chain competency leads to business success. Supply Chain Management Review, v.4, n.5, p.70-79, Jan.

BOWERSOX, D.J.; CLOSS, D.J. (1996). Logistical management: the integrated supply chain process. NY: McGraw-Hill.

BOWERSOX, D.J.; CLOSS, D.J. (2001). Logística Empresarial - O Processo de Integração da cadeia de suprimento. São Paulo, SP: Atlas.

CALVO, M. C. M. (2004). Estatística descritiva. Florianópolis: UFSC.

CHOW, G.; HEAVER, T. D.; HENRIKSSON, L. E. (1994). Logistics performance: definition and measurement. International Journal of Physical Distribution \& Logistics Management, Bradford, v. 24, n. 1, p. 17-28.

CHRISTOPHER, M. (1997). Logística e gerenciamento da cadeia de suprimentos: estratégias para redução de custos e melhoria dos serviços. São Paulo: Pioneira. 
Custos logísticos: mensuração e uso por redes supermercadistas do Estado do Rio Grande do Sul Marcos Antonio Souza, Rodrigo Machado Correa, Gustavo Pires Kruger

CRHISTOPHER, M. (1999). Logística e Gerenciamento da Cadeia de suprimentos: estratégia para redução de custos e melhoria de serviços, Ed. Pioneira: São Paulo.

CONCEICAO, Samuel Vieira; QUINTAO, Ronan Torres. (2004). Avaliação do desempenho logístico da cadeia brasileira de suprimentos de refrigerantes. Rev. Gestão \& Produção, v.11, n.3, p. 441-453.

COOKE, James A. (2006). Costs under pressure. Logistic Management, v.45, n.7, p.3437, July.

COOPER Martha C.; LAMBERT Douglas M.; PAGH Janus D. (1997). Supply chain management: more than a new name for logistics, v.8, p. 1-14.

COUNCIL OF SUPPLY CHAIN MANAGEMENT PROFESSIONALS- CSCMP (CONSELHO DOS PROFISSIONAIS DE GESTÃO DA CADEIA DE SUPRIMENTOS). (1998). Supply chain management and logistics management definitions. Disponível em: http://cscmp.org/AboutCSCMP/Definitions/Definitions.asp. Acesso em: 17/jul/2009.

DAHER, Cecílio Elias, SILVA, Edwin Pinto de La, FONSECA, Adelaida Pallavicine.(2006). Logística reversa: oportunidade para redução de custos através do Gerenciamento da cadeia integrada de valor. BBR - Brazilian Business Review, v. 3, n. 1, p. 58-73, jan/jun.

DE SANTA, Richard. (1998). Who's leading the leaders? Supermarket Business, v.53, n.2, p.15-18, fev.

FARIA, A. C.; COSTA, M. F. G. (2005). Gestão de custos logísticos. São Paulo: Atlas.

FÁVERO, L.P. Lopes; BELFIORE, P. Prado; DE ANGELO, C. (2005). Felisoni. Importância de variáveis organizacionais para a determinação de clusters no varejo supermercadista brasileiro. In: SEMINÁRIOS EM ADMINISTRAÇÃO - SEMEAD, VIII. São Paulo. Anais... São Paulo, FEA-AIP. CD-ROM.

FERREIRA, K. Araújo, ALVES, Maria R.P. Assumpção. (2005). Logística e troca eletrônica de informação em empresas automobilísticas e alimentícias. Revista Produção, v. 15, n. 3, p. 434-447, Set./Dez.

FERREIRA, M.A. Marques; VENÂNCIO, M. Moutinho; ABRANTES, L. Antonio. (2009). Análise da eficiência do setor de supermercados no Brasil. Economia Aplicada, v.13, n.2, p.333-347.

FLEURY, P. F., WANKE, P., FIGUEIREDO, K. F. (2000). Logística empresarial: a perspectiva brasileira. Coleção COPPEAD - Centro de estudos logísticos. São Paulo: Atlas. 
Custos logísticos: mensuração e uso por redes supermercadistas do Estado do Rio Grande do Sul Marcos Antonio Souza, Rodrigo Machado Correa, Gustavo Pires Kruger

FLEURY, P. F.; WANKE, P. (2003). Logística no Brasil. In: FIGUEIREDO, Kleber Fossati; FLEURY, Paulo Fernando; WANKE, Peter. (orgs.) Logística e gerenciamento da cadeia de suprimentos: planejamento do fluxo de produtos e dos recursos. Centro de Estudos em Logística. COPPEAD, UFRJ. São Paulo: Atlas.

GIÃO, P. Roberto; VASCONCELLOS, E.P. Gondim; OLIVEIRA JUNIOR, M. Miranda. (2008). Offshoring de atividades de pesquisa e desenvolvimento P\&D. IN: SEMINÁRIOS EM ADMINISTRAÇÃO FEA-USP, XI. Anais... São Paulo, FEA-USP. CDROM.

GIL, A. C. (1999). Métodos e técnicas de pesquisa social. (5 ed.). São Paulo, Atlas.

GOLDSBY, T., CLOSS, D. (2000). Using activity-based costing to reengineer the reverse logistic channel. International Journal of Physical distribution \& Logistics Management, v. 30, n.6, p. 500-511.

KOTLER, Philip, ARMOStRONG, Gary. (1999). Princípios de marketing. R. Janeiro: LTC.

LAIDENS, Graziela; TELES, C. Duarte; MÜLLER, C. José. (2007). Avaliação dos custos logísticos em empresas do setor alimentício. Estudos Tecnológicos, v.3, n.2, p.83-91, $\mathrm{Jul} / \mathrm{Set}$.

LAMBERT, Douglas M., COOPER, Martha C., PAGH, Janus D. (1998). Supply chain management: implementation issues and research opportunities, The International Journal of Logistics Management, v. 9, n 2, p. 1-20.

LAVRATTI, F.Beylouni; COLOSSI, Nelson; DE LUCA Marcelo. (2002). Considerações conceituais sobre efficient consumer response (ECR) no contexto supermercadista. Revista de Ciências da Administração, v.4, n.8, p. 75-88, jul/dez.

LEPSCH, S.L. (1996). Precificação em supermercados: um estudo exploratório junto a vinte empresas brasileiras. (Dissertação de Mestrado). USP, Faculdade de Economia e Administração. São Paulo: USP.

LEVY, Michael; WEITZ, Bartona. (2000). Administração de varejo. São Paulo: Atlas.

LIRA, R. Siqueira. (2005). Os custos da qualidade no processo de identificação, mensuração e eliminação dos desperdícios em supermercados varejistas: um estudo da comercialização e distribuição dos hortifrutigranjeiros em Taguatinga-DF. In: CONGRESSO USP DE CONTROLADORIA E CONTABILIDADE, V. Anais... São Paulo, FEA-USP. CD-ROM.

LOPES, R. del Cura; GUERRA, R. Perez; ANASTÁCIO, M. Regina. (2004). Análise dos custos logísticos na ótica do fornecedor supermercadista. In: ENCONTRO NACIONAL 
Custos logísticos: mensuração e uso por redes supermercadistas do Estado do Rio Grande do Sul Marcos Antonio Souza, Rodrigo Machado Correa, Gustavo Pires Kruger

DE ENGENHARIA DE PRODUÇÃO - ENEGEP, XXIV. Anais...Florianópolis, ENEGEP. CD-ROM.

MATHEWS, Ryan. (1996). Wanted: low-cost distribution. Progressive Grocer, v.75, n.1, p.39-40, Jan.

MEDEIROS NETO, João Paulo; MOTTA, K.R. Luna. (2006). Identificando estratégias de marketing nas redes de supermercados para frutas e hortaliças no Brasil. In: CONGRESSO DA SOCIEDADE BRASILEIRA DE ECONOMIA E SOCIOLOGIA RURAL - SOBER, XLIV. Fortaleza. Anais... Fortaleza, SOBER. CD-ROM.

NOVAES, A. (2004). Logística e gerenciamento da cadeia de distribuição. (2 ed.). Rio de Janeiro: Campus.

NOVACK, R.A; THOMAS, Douglas J. (2004). The challenges of implementing the perfect order concept. Transportation Journal. v. 43, n.1, p.5-16.

PARENTE, Juracy. (2000). Varejo no Brasil: gestão e estratégia. São Paulo: Atlas.

PETER, J.PAUL; CHURCHIL JR, GILBERT A. (2000). Marketing: criando valor para os clientes. (2 ed.). São Paulo: Saraiva.

PINTO, C. Damasceno. (2007). Análise da concorrência no setor de supermercados de Salvador na perspectiva de uma política antitruste. (Dissertação de Mestrado). Universidade de Salvador - UNIFACS. Salvador.

PIRES, S. R. I. (2004). Gestão da cadeia de suprimentos. São Paulo: Atlas.

POHLEN, Terrance L. e La LONDE, Bernard J. (1994). Implementing activity-based costing (ABC) in logistics. Journal of Business Logistics, v. 15, n. 2, p. 1-24.

PORTER, Michael E. (1986). Estratégia competitiva. Rio de Janeiro: Campus.

RAMPAZZO, Lino. (1998). Metodologia científica para alunos dos cursos de graduação e pós-graduação. São Paulo: Loyola.

RIBEIRO, Priscila C. Cabral, FERREIRA, Karine Araújo. (2003). Tecnologia da informação e logística: os impactos do EDI nas operações logísticas de uma empresa do setor automobilístico. In: ENCONTRO NACIONAL DE ENGENHARIA DE PRODUÇÃO - ENEGEP, XXIII. Anais...Ouro Preto (MG), ENEGEP. CD-ROM.

RICARTE, M.A.Chaves. (2005). A logística em pequenos supermercados e o papel da tecnologia de informação: um estudo de caso em uma associação de supermercados. (Dissertação de Mestrado), UNIFOR. 
Custos logísticos: mensuração e uso por redes supermercadistas do Estado do Rio Grande do Sul Marcos Antonio Souza, Rodrigo Machado Correa, Gustavo Pires Kruger

SAAB, W.G. Lopes; GIMENES, L.C. Perez; RIBEIRO, R. Martins. (2000). Supermercados no Brasil: movimento das empresas menores. BNDES, Área de Operações Industriais 2. - Gerência Setorial de Comercio e Serviços, nota n. 24, dezembro.

Disponível

em: http://www.bndes.gov.br/SiteBNDES/export/sites/default/bndes_pt/Galerias/Arquivos/co nhecimento/setorial/get4is24.pdf. Acesso em 15/out/2009.

SANTOS, A.M.M.M.; GIMENEZ, L.C. P.; MATTOS, C. Barbosa. (1998). Hiper e supermercados no Brasil. BNDES - Gerência Setorial de Comércio e Serviços. Disponível em: http://www.bndes.gov.br/SiteBNDES/export/sites/default/bndes_pt/Galerias/Arquivos/co nhecimento/relato/hiperm3.pdf. Acesso em: 15/set/2009.

SANTOS, Anderson. (2006). Centros de distribuição como vantagem competitiva. Revista de Ciências Gerenciais, v.10, n.12, p.34-40.

SGUISSARDI, Valdemar. (2008). Modelo de expansão da educação superior no Brasil: predomínio privado/mercantil e desafios para a regulação e a formação universitária. Educação \& Sociedade, v.29, n.105, p.991-1022.

SILVA, De Plácio. (1995). Vocabulário jurídico. (3 ed.). Rio de Janeiro: Forense, volume $\mathrm{V}$.

SILVA, Edna Lúcia; MENEZES, Estera Muskat. (2001). Metodologia da pesquisa e elaboração de dissertação. (3 ed.). Florianópolis: Laboratório de Ensino à Distância da UFSC.

SILVEIRA, Luiz. (2006). Setor orgânico se une para escoar produção. Jornal DCl. Disponível em: http://www.cartadelogistica.com.br/website/text.asp?txtCode=16123\&txtDate. Acesso em 10/set/2009.

SOUZA, M.A.Ferreira; ALMEIDA, Kátia. (2007). Globalização do varejo supermercadista: uma análise da influência sobre o formato e dinâmica do funcionamento do sistema agroalimentar. In: CONGRESSO DA SOCIEDADE BRASILEIRA DE ECONOMIA E SOCIOLOGIA RURAL - SOBER, XLV. Anais...Londrina, SOBER. CD-ROM

VERGARA, S. C. (2003). Projetos e relatórios de pesquisa em administração. São Paulo: Atlas.

WERNER, Alexandre; SEGRE, L. Micaela. (2008). Uma análise do segmento de supermercados: estratégias, tecnologias e emprego. Boletim Técnico do Senac, v.28, jan/abr. Disponível em: http://senac.br/BTS/281/boltec281e.htm. Acesso em: 15/Out/ 2009. 
Custos logísticos: mensuração e uso por redes supermercadistas do Estado do Rio Grande do Sul

WOOD JR., Thomaz; ZUFFO, Paulo K. (1998). Supply chain management. RAE-FGV, v.38, n.3, p.55-63, jul/set.

XAVIER, S.C.; GIULIANI, A.C.; SPERS, V.R.E. (2006). Um estudo das ferramentas de marketing utilizados pelo Supermercado Versailles Rede Smart. Disponível em: http://www.unimep.br/phpg/mostraacademica/anais/4mostra/pdfs/488.pdf. Acesso em: 15/Set/2009.

YIN, Roberto K. (2001). Estudo de caso: planejamento e métodos. Porto Alegre: Bookman.

YOSHIZAKI, Hugo; VIDAL, José Geraldo. (2007). Avaliando o estado atual da colaboração logística na cadeia do varejo supermercadista. Revista Tecnologística, n.239, p.134-136, jun.

ZANQUETTO F. H.; PIZOLATTO, Nélio D. (2003). Os sistemas de custeio na avaliação de desempenho da supply chain. Revista da Administração FAESA, v. 1, n. 2.

Data de Submissão: 02/12/2009

Data de Aceite: 12/01/2011 